\title{
Distinct Effects of Hedgehog Signaling on Neuronal Fate Specification and Cell Cycle Progression in the Embryonic Mouse Retina
}

\author{
Kiyo Sakagami, ${ }^{1}$ Lin Gan, ${ }^{3}$ and Xian-Jie Yang ${ }^{1,2}$ \\ ${ }^{1}$ Jules Stein Eye Institute and Department of Ophthalmology, and ${ }^{2}$ Molecular Biology Institute, David Geffen School of Medicine, University of California, \\ Los Angeles, Los Angeles, California 90095, and ${ }^{3}$ Department of Ophthalmology, University of Rochester, Rochester, New York 14642
}

Cell-extrinsic signals can profoundly influence the production of various neurons from common progenitors. Yet mechanisms by which extrinsic signals coordinate progenitor cell proliferation, cell cycle exit, and cell fate choices are not well understood. Here, we address whether Hedgehog $(\mathrm{Hh})$ signals independently regulate progenitor proliferation and neuronal fate decisions in the embryonic mouse retina. Conditional ablation of the essential Hh signaling component Smoothened (Smo) in proliferating progenitors, rather than in nascent postmitotic neurons, leads to a dramatic increase of retinal ganglion cells (RGCs) and a mild increase of cone photoreceptor precursors without significantly affecting other early-born neuronal cell types. In addition, Smo-deficient progenitors exhibit aberrant expression of cell cycle regulators and delayed $G_{1} / S$ transition, especially during the late embryonic stages, resulting in a reduced progenitor pool by birth. Deficiency in Smo function also causes reduced expression of the basic helix-loop-helix transcription repressor Hes 1 and preferential elevation of the proneural gene Math5. In Smo and Math5 double knock-out mutants, the enhanced RGC production observed in Smo-deficient retinas is abolished, whereas defects in the $\mathrm{G}_{1} / \mathrm{S}$ transition persist, suggesting that Math5 mediates the Hh effect on neuronal fate specification but not on cell proliferation. These findings demonstrate that Hh signals regulate progenitor pool expansion primarily by promoting cell cycle progression and influence cell cycle exit and neuronal fates by controlling specific proneural genes. Together, these distinct cellular effects of Hh signaling in neural progenitor cells coordinate a balanced production of diverse neuronal cell types.

\section{Introduction}

The mature vertebrate retina consists of seven specific neuronal cell types uniquely devoted to sensing and processing visual information. Retinal ontogeny follows an evolutionarily conserved order, with retinal ganglion cells (RGCs), horizontal cells, cone photoreceptors, and amacrine cells first becoming postmitotic, followed by a late wave of cell birth giving rise to rod photoreceptors, bipolar cells, and Müller glia (Young, 1985a,b; Spence and Robson, 1989; Altshuler et al., 1991). Cell lineage tracing and molecular genetic analyses have revealed that the interplay between cell-extrinsic cues and cell-intrinsic factors is critical for the formation of a functional retinal network (Turner and Cepko, 1987; Holt et al., 1988; Wetts and Fraser, 1988; Lillien, 1995; Furukawa et al., 1997a; Mears et al., 2001; Vetter and Brown, 2001; Viczian et al., 2003; Mu et al., 2005; Ohsawa and Kageyama, 2008; Pan et al., 2008). However, the precise mechanisms by

Received Jan. 17, 2009; revised March 31, 2009; accepted April 22, 2009

This work was in part supported by grants from Research to Prevent Blindness Foundation, the Karl Kirchgessner Foundation, and the National Eye Institute (X.J.Y.). We thank Drs. Connie Cepko and Andy McMahon for transgenic animals, Dr. Richard Behringer for the Lim1 antibody, Dr. Hiroshi Sasaki for the Gli1 CDNA, Dr. Ingrid Schmid for assistance on flow cytometry, and Dr. Xiang-Mei Zhang for assistance on in situ hybridization.

Correspondence should be addressed to Xian-Jie Yang, Jules Stein Eye Institute, David Geffen School of Medicine, University of California, Los Angeles, 100 Stein Plaza, Los Angeles, CA 90095. E-mail: yang@jsei.ucla.edu. D01:10.1523/JNEUROSCI.0289-09.2009

Copyright $\odot 2009$ Society for Neuroscience $\quad$ 0270-6474/09/296932-13\$15.00/0 which extracellular signals coordinate progenitor cell behaviors are not well understood.

The hedgehog $(\mathrm{Hh})$ family of molecules affects multiple aspects of retinogenesis. In early neurogenesis, Sonic hedgehog (Shh) derived from first-born RGCs promotes propagation of the neurogenic wave front (Neumann and Nuesslein-Volhard, 2000) but suppresses RGC genesis as these neurons accumulate (Zhang and Yang, 2001; Yang, 2004; Wang et al., 2005). Shh signals also appear to influence the growth and trajectory of RGC axons (Kolpak et al., 2005; Sánchez-Camacho and Bovolenta, 2008). In zebrafish, reduction of $\mathrm{Hh}$ activities affects differentiation of late cell types including Müller glia, bipolar cells, GABAergic amacrine cells, and photoreceptors (Stenkamp and Frey, 2003; Shkumatava et al., 2004). Furthermore, laminar organization of the retina is disrupted in Shh mutants (Wang et al., 2002; Shkumatava et al., 2004).

Despite the established function of Shh as a mitogen in several compartments of the CNS (for review, see Ruiz i Altaba et al., 2002; Cayuso et al., 2006), the precise role of $\mathrm{Hh}$ in retinal proliferation remains controversial. In rodents, recombinant Shh-N promotes retinal progenitor proliferation in cultures (Jensen and Wallace, 1997; Levine et al., 1997), and partial depletion of Shh decreases proliferation (Wang et al., 2005). In Xenopus, inhibiting Hh signals hinders cell cycle progression (Locker et al., 2006; Agathocleous et al., 2007). However, in zebrafish, $H$ h mutation 
appears to cause a prolonged period of cell proliferation (Shkumatava and Neumann, 2005).

In this study, we examined mechanisms through which $\mathrm{Hh}$ signals affect important behaviors of neural progenitors by analyzing conditional mutants of the essential Hh signaling component Smoothened (Smo) (Alcedo et al., 1996; van den Heuvel and Ingham, 1996) and double mutants of Smo and the proneural gene Math5 (Kanekar et al., 1997; Brown et al., 1998, 2001; Wang et al., 2001). We provide conclusive evidence that Hh signals profoundly influence progenitor cell proliferation and affect fate decisions of specific neuronal types. Furthermore, we show that distinct Hh signaling effects are mediated by different intracellular machineries during the neurogenic cell cycle. These findings thus provide mechanistic insights on how cell-extrinsic cues coordinate neural network formation.

\section{Materials and Methods}

Animals. Mice carrying the floxed Smo allele (Smo ${ }^{\text {flox }}$ ) (Long et al., 2001) and the Chx10-Cre transgene (Rowan and Cepko, 2004) were obtained from The Jackson Laboratory. Mice encoding Cre in the Math5 locus $\left(\right.$ Math $5^{\mathrm{Cre}-k i}$ ) were previously described (Yang et al., 2003). All three lines were backcrossed into the C57BL/6J background for a minimum of three generations. To generate Smo conditional knock-out mice, homozygous $S m o^{\text {flox } / \text { flox }}$ females were crossed with either $\mathrm{Smo}^{\text {flox/+ }}$;Chx10-Cre or Smo ${ }^{\text {flox/+ }} ;$ Math $^{\text {Cre-ki/+ }}$ male mice. To generate Smo and Math 5 double knock-out mice, Smo flox/flox; $M a t h 5^{\text {Cre-ki/Cre-ki }}$ females were crossed with Smo flox/+ ${ }^{\text {Math }} 5^{\mathrm{Cre}-k i /+}$;Chx10-Cre male mice. Genotypes were determined by PCR using primers listed in supplemental Table 1 (available at www.jneurosci.org as supplemental material). Animal procedures were approved by University of California Los Angeles Animal Research Committee.

Immunohistochemistry. Immunolabeling was performed as previously described (Zhang and Yang, 2001; Hashimoto et al., 2006). Retinal cryosections fixed in $4 \%$ paraformaldehyde were incubated with the following primary antibodies against Brn3a (1:100; Millipore Bioscience Research Reagents), green fluorescent protein (GFP) (1:500; Invitrogen), $\beta$-tubulin ( $\beta$ Tub) (1:800; Covance), cone-specific G-protein $\gamma$ subunit $(\mathrm{G} \gamma \mathrm{C})$ (1:1000; Cytosignal), Pax6 (1:1000; Millipore Bioscience Research Reagents), AP2 $\alpha$ (1:4; Developmental Studies Hybridoma Bank), NF145 (1:1000; Millipore Bioscience Research Reagents), and 5-bromo-2deoxyuridine (BrdU) (1:100; Abcam). Secondary antibodies conjugated with Alexa 488 or Alexa 594 (1:500; Invitrogen) were used. In vivo BrdU incorporation was conducted by intraperitoneal injection of $2.5 \mathrm{mg}$ of BrdU per female $24 \mathrm{~h}$ before animals were killed. Sections were treated with $4 \mathrm{~N} \mathrm{HCl}$ for 5 min before incubation with anti-BrdU antibody. Immunofluorescent images were captured using a Nikon E800 microscope or a laser scanning confocal microscope (Leica TCS-SP).

In situ hybridization. In situ hybridization was performed using digoxigenin-labeled RNA probes as previously described (Yang and Cepko, 1996). Mouse Otx2, Crx, Ngn2, Math3, and cyclin D1 cDNAs were generated by reverse transcription followed by PCR using primers listed in supplemental Table 2 (available at www.jneurosci.org as supplemental material) and authenticated by DNA sequencing. Math5 and Gli1 cDNAs were previously described (Sasaki et al., 1999; Wang et al., 2001).

Flow cytometry. Dissected retinas were dissociated with $0.1 \%$ trypsin (Sigma-Aldrich) in calcium/magnesium-free (CMF) HBSS (Invitrogen) for $15 \mathrm{~min}$ at $37^{\circ} \mathrm{C}$. Dissociated cells were fixed in $0.25 \%$ paraformaldehyde in HBSS for $30 \mathrm{~min}$ at room temperature followed by incubation with $0.1 \%$ Triton X-100 in HBSS. Antibodies were diluted in CMF HBSS containing $1 \%$ fetal calf serum (FCS), $0.2 \%$ goat serum, $0.2 \%$ donkey serum, and $0.1 \%$ Triton X-100. For BrdU staining, cells were first treated with $0.2 \mathrm{~N} \mathrm{HCl}$ and washed once with CMF HBSS. Cells were incubated for $60 \mathrm{~min}$ at room temperature with the following primary antibodies against proliferating cell nuclear antigen (PCNA) (1:100; SigmaAldrich), GFP (1:500; Invitrogen), NF145 (1:1000; Millipore Bioscience Research Reagents), Brn3a (1:100; Millipore Bioscience Research Reagents), $\beta$ Tub (1:800; Covance), Crx (1:100; Abnova), G $\gamma \mathrm{C}$ (1:1000;
Cytosignal), AP2 $\alpha$ (1:4; Developmental Studies Hybridoma Bank), calbindin (1:500; Millipore Bioscience Research Reagents), cyclin D1 (1: 100; Millipore Bioscience Research Reagents), Lim1 (1:200) (Poché et al., 2007), p2 $7^{\text {Kip1 }}$ (1:100; BD Biosciences), p57 Kip2 (1:20; Santa Cruz Biotechnology), and $\mathrm{BrdU}$ (1:2; GE Healthcare). Cells were then washed once with HBSS containing $0.1 \%$ Triton X-100 and incubated for $30 \mathrm{~min}$ at room temperature with $10 \mu \mathrm{g} / \mathrm{ml} \mathrm{4',6-diamidino-2-phenylindole}$ (DAPI) (Roche) and Alexa 488- or Alexa 647-conjugated secondary antibodies. Flow cytometry was performed using an LSR flow cytometer (BD Biosciences) and analyzed with CellQuest (BD Biosciences), Modfit (BD Biosciences), and FlowJo (Tree Star) software.

Retinal cultures. Retinal explants were pulse-labeled with $25 \mu \mathrm{M} \mathrm{BrdU}$ in basal medium (10 mM HEPES, pH 7.0, in DMEM and F12 at a 1:1 ratio) containing 5\% FCS and penicillin/streptomycin, and then transferred onto $0.4 \mu \mathrm{m}$ pore size Minicell membrane (Millipore) and cultured for $0-21 \mathrm{~h}$ at $37^{\circ} \mathrm{C}$ in $5 \% \mathrm{CO}_{2}$.

Real-time PCR. Each sample combined multiple embryonic day 15.5 (E15.5) retinas according to the genotypes, and total RNAs were purified by ISOGEN (Nippongene). Single-stranded cDNAs were prepared using Superscript III (Invitrogen). The cDNA derived from $10 \mathrm{ng}$ of RNA and $100 \mathrm{~nm}$ each primer were used for a single reaction. The reactions were performed for 40 cycles with annealing at $60-62^{\circ} \mathrm{C}$ for $15 \mathrm{~s}$ followed by extension at $95^{\circ} \mathrm{C}$ for $1 \mathrm{~min}$ using real-time PCR master mix containing SYBR Green (Applied Bioscience) and StepOne real-time PCR system (Applied Bioscience). Real-time PCR data were normalized with $18 \mathrm{~S}$ ribosomal RNA. The primers used were either designed by using Primer3 (http://frodo.wi.mit.edu/) or selected from a primer bank (http:// pga.mgh.harvard.edu/primerbank/index.html) (supplemental Table 2, available at www.jneurosci.org as supplemental material).

Statistical analysis. For quantification of cells plated and immunolabeled as a monolayer, a minimum of 300 and up to 1000 cells per sample was quantified using ImagePro PLUS software (Media Cybernetics). For flow cytometry, a minimum of 30,000 cells was analyzed per sample. Data were presented as mean \pm SEM. For all pairwise analyses, the Student $t$ test was used. For comparison of multiple sample groups, ANOVA analyses followed by the Tukey-Kramer test were performed (Hsu, 1996). Values of $p<0.05$ were considered statistically significant.

\section{Results \\ Hh signaling is required cell autonomously by proliferating progenitors}

To completely eliminate the cellular response to Hh signals, we performed retina-specific ablation of the Smo gene, which is essential for signal transduction of all known Hh ligands (Alcedo et al., 1996; van den Heuvel and Ingham, 1996). To determine the temporal requirement for Hh signaling, mice encoding floxed Smo alleles $\left(S m o^{f l o x}\right)$ (Long et al., 2001) were first crossed with a mouse line in which the Cre gene had replaced the Math5 gene $\left(\right.$ Math5 $5^{\text {cre-ki }}$ ) (Yang et al., 2003). Math5 expression is normally found in a subset of progenitor cells poised to exit the mitotic cell cycle and in nascent postmitotic RGCs as early as E11.5 (Brown et al., 1998; Wang et al., 2001; Le et al., 2006). Test crosses between Math $5^{\text {cre-ki }}$ and ROSA26R lacZ Cre reporter mice (Soriano, 1999) showed that nearly all of $\beta$-Gal-positive cells resided in the retinal RGC layer at E15.5 (data not shown). Thus, Cre function in Math $5^{\text {cre-ki }}$ mice was active in cells that were either exiting or had exited the cell cycle to give rise to postmitotic RGCs. Additional analyses revealed no difference in embryonic neuronal production among the control (Smo flox/flox; Math $\left.5^{+/+}\right)$, Smo heterozygous $\left(\mathrm{Smo}^{\text {flox } /+}\right.$; Math $\left.5^{\text {cre-ki/+ }}\right)$, and the conditional knock-out Smo mutant retinas (Smo flox/flox Math $^{\text {cre-ki/++}}$ ) (data not shown). These results suggested that Smo activity was likely involved at an earlier stage before retinal progenitor withdrawal from the cell cycle.

To delete Smo in cycling retinal progenitors, we used a Chx10Cre transgenic mouse line (Rowan and Cepko, 2004). Under the 
Chx10 promoter control, this mouse line expresses a fully active Cre-GFP fusion protein at E11.5 with a varying degree of mosaicism (Rowan and Cepko, 2004). At E12.5, when only a few cells expressed the RGC cell marker Brn3a (Liu et al., 2000; Wang et al., 2002), the majority of retinal progenitors were positive for GFP, indicating that Cre expression in retina of the Chx10-Cre mouse was initiated before the onset of retinogenesis (Fig. $1 A-C$ ). By E14.5, GFP signals persisted at high levels in the ventricular zone occupied by proliferating progenitor cells but diminished greatly in the inner retina occupied by postmitotic neurons (Fig. $1 D-G$ ). Therefore, the Cre-GFP fusion protein appeared to be labile in retinal cells that had exited the cell cycle.

We next performed genetic ablation of Smo using the Chx10-Cre mouse to provide Cre in the retina. Quantitative realtime PCRs were performed to evaluate the effects of Smo ablation on expression of Hh signaling components (Fig. 1P). At E15.5, compared with control retinas with two functional copies of Smo alleles $\left(S m o^{\text {flox } / \text { flox }} ;+1+\right.$, hereafter referred to as Smo ${ }^{+/+}$), Smo homozygous conditional knock-out mutant retinas $\left(S m o^{\text {flox } / \text { flox; }}\right.$ Chx10-Cre, hereafter referred to as Smo ${ }^{-1-}$ cKO mutant) contained a very low level of Smo transcripts (5.0\%) and a severely reduced level of Ptc1 (34.8\%), the $\mathrm{Hh}$ receptor and a direct target of $\mathrm{Hh}$ signaling (Fig. $1 P$ ). Furthermore, expression levels of all three $\mathrm{Hh}$ signaling effectors, Gli1, Gli2, and Gli3, showed 69.3, 58.6, and $16.5 \%$ reduction, respectively (Fig. $1 P$ ). These data indicate that Hh signal transduction is severely impaired in Chx10Cre-mediated Smo cKO retinas.

At postnatal day $0(\mathrm{P} 0), \mathrm{Smo}^{-1-} \mathrm{cKO}$ mutant retinas showed severe phenotypes compared with their heterozygous littermates (Smo flox/+ ; Chx10-Cre, hereafter referred to as $\mathrm{Smo}^{+1-}$ ). The $\mathrm{Smo}^{-1-} \mathrm{cKO}$ retinas were smaller in size and displayed a reduced ventricular zone and an expanded inner retina (Fig. $1 H-M$ ). Consistent with the mosaic expression of Cre-GFP, cross sections of Smo cKO retinas showed occasional radially orientated columns without GFP signals (Fig. $1 L, M$ ). These Cre-negative regions appeared to resemble the wild-type retinas in morphology (Fig. $1 L, M$; supplemental Fig. 1, available at www.jneurosci.org as supplemental material). Furthermore, quantification by flow cytometry using PCNA as a progenitor cell marker showed that, at E15.5, control Smo ${ }^{+/+}$and $\mathrm{Smo}^{+/-}$ retinas contained identical proportions of progenitor cells, whereas $\mathrm{Smo}^{-1-} \mathrm{cKO}$ retinas contained significantly reduced progenitor cells compared with $\mathrm{Smo}^{+/+}$controls $(60.8-$ $52.5 \%$ ) (Fig. $1 \mathrm{~N}$ ). By E17.5, Smo ${ }^{-1-} \mathrm{cKO}$ retinas showed a nearly $40 \%$ reduction of GFP-positive cells (57.7-34.7\%), the presumptive retinal progenitors (Fig. 1O). indicate SEM.
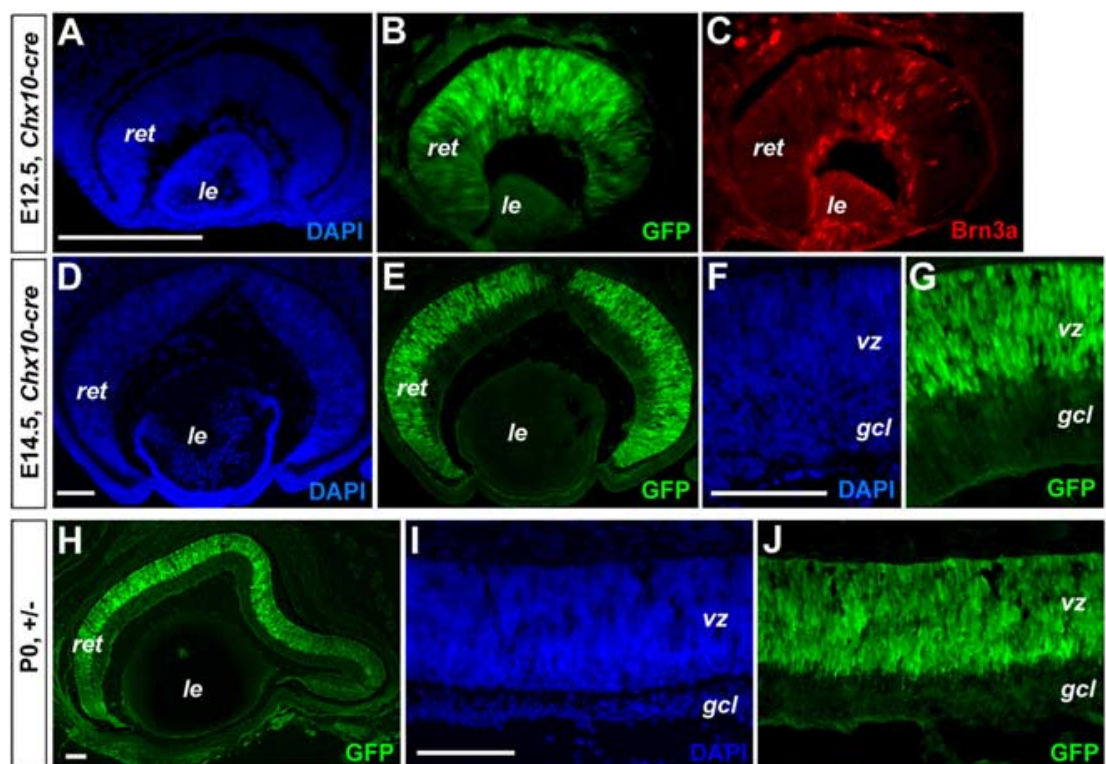

Figure 1. Expression of Chx10-cre and phenotypes of Chx10-cre induced Smo ablation. A-G, Expression of Cre-GFP fusion protein in E12.5 (A-C) and E14.5 (D-G) retinas of the Chx10-cre transgenic mouse. Retinal sections were labeled by DAPI for nucle Cre-GFP-expressing retinal progenitor cells at PO. Retinal sections from Smo heterozygous $(\boldsymbol{H}-\boldsymbol{J})$ and Smo cKO mutants $(\boldsymbol{K}-\boldsymbol{M})$ were labeled by anti-GFP $(\boldsymbol{H}, \boldsymbol{J}, \boldsymbol{K}, \boldsymbol{M})$ and DAPI $(\boldsymbol{I}, \boldsymbol{L})$. $\boldsymbol{I}$ and $\boldsymbol{L}$ show the same sections as in $\boldsymbol{J}$ and $\boldsymbol{M}$, respectively. The white dotted $\boldsymbol{A}$ (for $\boldsymbol{A}-\boldsymbol{C}), \boldsymbol{D}$ (for $\boldsymbol{D}, \boldsymbol{E}), \boldsymbol{F}$ (for $\boldsymbol{F}, \boldsymbol{G}), \boldsymbol{H}$ (for $\boldsymbol{H}, \boldsymbol{K}), \boldsymbol{I}($ for $\boldsymbol{I}, \boldsymbol{J}, \boldsymbol{L}, \boldsymbol{M}), 100 \mu \mathrm{m} . \boldsymbol{N}, \mathbf{0}$, Quantification of retinal progenitor cells by flow cytometry. Percentages of PCNA-positive cells among total cells at E15.5 $(\boldsymbol{N})$ and GFP-positive cells among total cells at E17.5 (0) presented as ratios of Smo CKO mutants $(-1-)$ versus Smo controls $(+/+)$ normalized according to 18S rRNA $(n=3)$. of individual retinas analyzed are indicated below the bar graphs. ${ }^{* *} p<0.01,{ }^{* *} p<0.001$, and ${ }^{* * * *} p<0.0001$. Error bars

Together, these results provide definitive evidence that, during normal mouse retinal development, Smo function is required cell autonomously by proliferating retinal progenitors before their withdrawal from the cell cycle.

Loss of Smo function greatly enhances retinal ganglion cell production

The expanded inner retina in Smo cKO mutants suggested that Hh signaling deficiency affected early retinogenesis. We therefore characterized the effects of Smo ablation on the commitment of progenitor cells toward the RGC fate. Immunostaining by the neuronal marker $\beta$ Tub detected similar labeling patterns in $\mathrm{Smo}^{+1+}$ and $\mathrm{Smo}^{+/-}$retinas (Fig. $2 A, B$ ). In contrast, the $S m o^{-1-}$ cKO retina showed expanded $\beta$ Tub labeling in the inner 


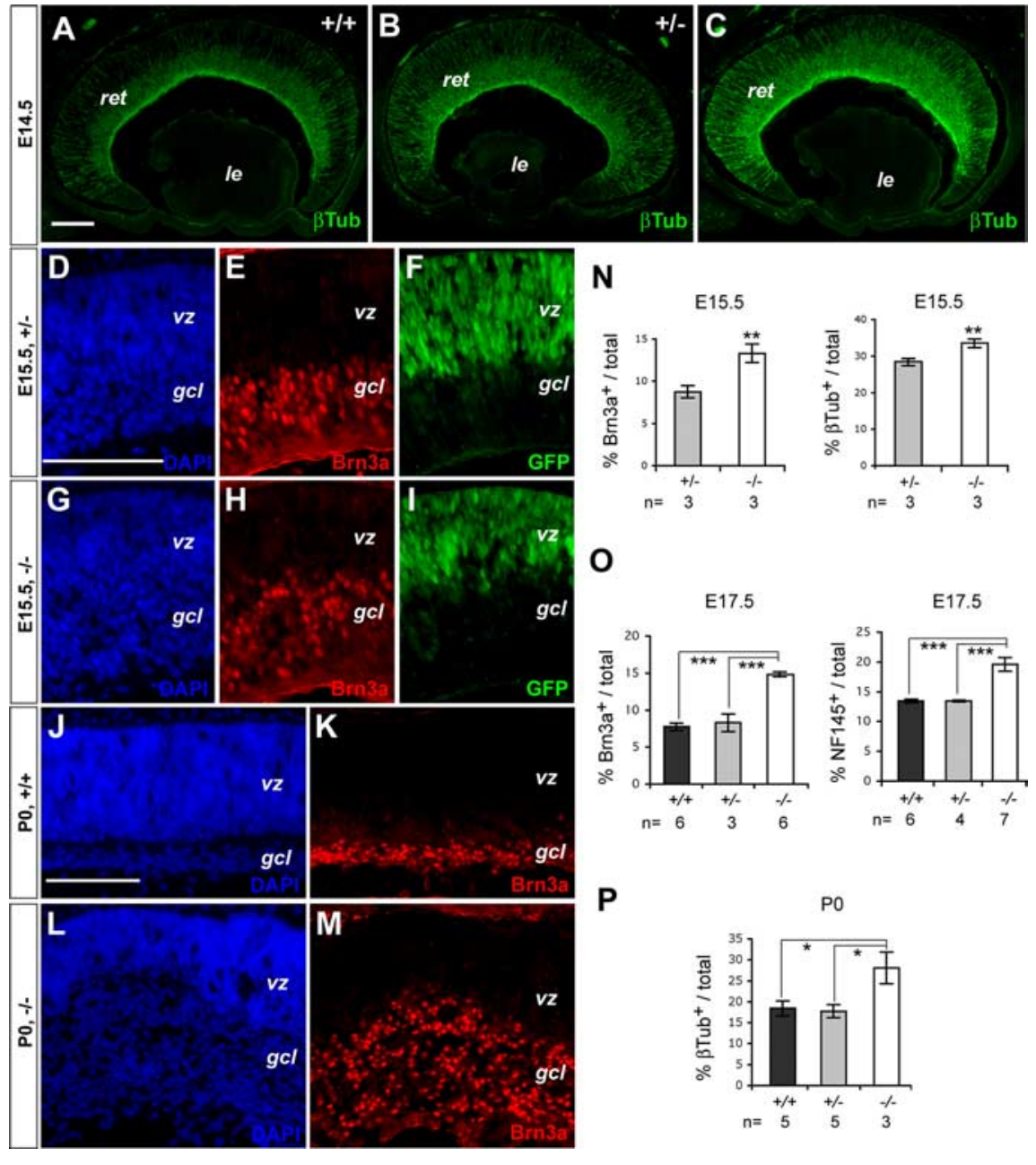

Figure 2. Enhanced retinal ganglion cell production in Smo mutant retinas. $\boldsymbol{A}-\boldsymbol{M}$, Immunofluorescent labeling of E14.5 (A-C), E15.5 $(\boldsymbol{D}-\boldsymbol{I})$, and P0 $(\boldsymbol{J}-\boldsymbol{M})$ retinas. Sections of control $(+/+)(\boldsymbol{A}, \boldsymbol{J}, \boldsymbol{K})$, Smo heterozygous $(+/-)(\boldsymbol{B}, \boldsymbol{D}-\boldsymbol{F})$, and Smo cKO mutant retinas (-I-) $(\boldsymbol{C}, \boldsymbol{G}-\boldsymbol{I}, \boldsymbol{L}, \boldsymbol{M})$ were labeled for $\beta$ Tub $(\boldsymbol{A}-\boldsymbol{C})$, colabeled for DAPI, Brn3a and GFP (D-F; and $\mathbf{G}-\boldsymbol{I})$, and colabeled for DAPI and Brn3a $(\boldsymbol{J}, \boldsymbol{K}$; and $\boldsymbol{J}, \boldsymbol{M})$. gcl, Ganglion cell layer; le, lens; ret, retina; $v z$, ventricular zone. Scale bars: $\boldsymbol{A}$ (for $\boldsymbol{A}-\boldsymbol{C}), \boldsymbol{D}$ (for $\boldsymbol{D}-\boldsymbol{I}), \boldsymbol{J}($ for $\boldsymbol{J}-\boldsymbol{M}), 100 \mu \mathrm{m} . \boldsymbol{N}-\boldsymbol{P}$, Quantification of RGCs by flow cytometry. Percentages of marker positive cells

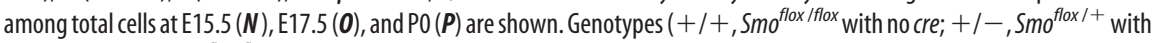
Chx10-cre; - I-,Smo flox /flox with $(h \times 10-(r e)$, and numbers $(n)$ of individual retinas analyzed are indicated below the bar graphs. ${ }^{*} p<0.05,{ }^{* *} p<0.01$, and ${ }^{* * *} p<0.001$. Error bars indicate SEM.

retina as well as increased $\beta$ Tub-positive processes throughout the ventricular zone (Fig. 2C). Additional analyses using the RGC-specific marker Brn3a showed that, at E15.5, the RGC layer in $S m o^{-I-}$ cKO mutants was already expanded (Fig. $2 D-I$ ). By $\mathrm{P} 0$, in contrast to control $S m o^{+/+}$retinas, which contained a well defined RGC layer (Fig. $2 J, K$ ), Brn3a-positive RGCs in Smo ${ }^{-1-}$ $\mathrm{cKO}$ retinas were spread over the inner one-half of the retina with concomitant shrinking of the proliferative zone (Fig. $2 L, M$ ).

Quantitative marker analyses further confirmed the enhanced RGC production in $\mathrm{Smo}^{-1-}$ cKO mutants. As early as E15.5, $\mathrm{Smo}^{-1-}$ retinas showed significant increases in Brn3a-positive $(8.8-13.3 \%)$ and $\beta$ Tub-positive neurons (28.4-33.5\%) (Fig. $2 \mathrm{~N})$. At E17.5, heterozygous $\mathrm{Smo}^{+/-}$and control $\mathrm{Smo}^{+/+}$retinas contained comparable proportions of RGCs as measured by Brn3a and the neurofilament marker NF145 (Fig. 2O). In contrast, loss of both $S m o$ alleles resulted in a near doubling of Brn3apositive RGCs (7.7-14.8\%) and a significant increase in NF145positive cells (13.4-19.6\%) compared with controls (Fig. 2O). Consistent with Brn3a immunolabeling patterns at P0, Smo ${ }^{-1-}$ cKO retinas contained a $51 \%$ increase of $\beta$ Tub-positive cells
(18.5-28.1\%) (Fig. 2P). These results demonstrate that the blockade in Hh signaling before the onset of retinogenesis severely affects RGC fate specification among early retinal progenitor cells.

\section{Smo deficiency only mildly influences} cone photoreceptor production

Cone photoreceptor cells are among the earliest born retinal neurons. Previous studies have shown that the homeodomain protein Otx2 regulates transcription of the Crx homeobox gene that is required for photoreceptor differentiation (Chen et al., 1997; Furukawa et al., 1997b, 1999; Nishida et al., 2003; Viczian et al., 2003). We therefore tested the influence of $\mathrm{Hh}$ signaling on cone photoreceptor genesis by examining Otx 2 and $C r x$ expression. In situ hybridization of E15.5 Smo ${ }^{+/+}$, $\mathrm{Smo}^{+/-}$, and $\mathrm{Smo}^{-1-} \mathrm{cKO}$ mutant retinas revealed similar distributions of Otx2 and Crx transcripts in the ventricular zone and near the ventricular surface, where postmitotic cone cells accumulated (Fig. $3 A-$ $F)$. In addition, immunostaining by an antibody recognizing the cone-specific $\mathrm{G} \gamma \mathrm{C}$ also detected similar labeling patterns among $\mathrm{Smo}^{+/+}, \mathrm{Smo}^{+/-}$, and $\mathrm{Smo}^{-1-}$ cKO mutant retinas at E15.5 (Fig. 3G-I).

To detect potential minor effect of Smo deficiency on photoreceptor production, we used flow cytometry to analyze a large number of retinal cells by labeling for photoreceptor precursor marker Crx and cone precursor marker G $\gamma$ C. At both E15.5 and E17.5, mild yet statistically significant increases of Crx-positive cells were detected in $\mathrm{Smo}^{-1-}$ cKO retinas compared with control retinas $(11.9-14.6 \%$ at E15.5; $18.9-22.7 \%$ at E17.5) (Fig. 3J). At E17.5, $\mathrm{Smo}^{-1-} \mathrm{cKO}$ retinas showed slightly higher but not statistical significant levels of $\mathrm{G} \gamma \mathrm{C}$-positive cells compared with the control retinas (Fig. $3 \mathrm{~K}$ ). These results show that, in addition to influencing RGC genesis, early Hh signaling deficiency also results in a mild increase in cone photoreceptor production.

\section{Smo deficiency influences a subset of early-born retinal neurons}

To determine whether disruption of Hh signaling in retinal progenitors affects development of all early-born retinal neurons, we analyzed the production of horizontal cells and amacrine cells. Quantification by flow cytometry using AP2 $\alpha$, an amacrine cell marker (West-Mays et al., 1999), calbindin, a marker expressed in a subtype of amacrine cells and horizontal cells (Dyer and Cepko, 2001a), and Lim1, an early marker for postmitotic horizontal cells (Poché et al., 2007), did not detect significant alterations at E17.5 (supplemental Fig. $2 A-C$, available at www.jneurosci.org as supplemental material). Compared with the controls, immunostaining of $\mathrm{Smo}^{-1-} \mathrm{cKO}$ retinas at $\mathrm{P} 0$ did not reveal changes in AP2 $\alpha$-positive cells despite the dispersion of these cells (supplemental Fig. 2, available at www.jneurosci.org as supplemental material). 
Furthermore, immunolabeling for NF145 detected similar patterns of differentiating horizontal cells located within the ventricular zone of $\mathrm{Smo}^{+/+}, \mathrm{Smo}^{+/-}$, and $\mathrm{Smo}^{-1-}$ cKO retinas (supplemental Fig. 2, available at www.jneurosci.org as supplemental material), indicating that horizontal cell production was not affected. These results thus demonstrate that Hh signals preferentially regulate the production of a subset of earlyborn retinal neurons but have minimum effects on amacrine cell and horizontal cell specification.

\section{Hh signaling differentially regulates neurogenic factors}

To probe mechanisms underlying the differential influence of Hh signaling on retinal cell type specification, we analyzed expression of basic helix-loop-helix (bHLH) transcription factors. In situ hybridization detected a marked increase of Math5 transcripts, which is required for RGC fate determination (Brown et al., 2001; Wang et al., 2001), in the ventricular zone in Smo $^{-1-}$ cKO mutants at E15.5 (Fig. 4AC). Furthermore, Math 5 transcripts were also detected in the inner retina occupied by postmitotic RGCs, indicating that Math5 expression was sustained in $\mathrm{Smo}^{-1-}$ RGCs, which normally only transiently express Math5 (Fig. 4A-C). In contrast, expression patterns of bHLH genes $N g n 2$ and Math3, which are involved in retinal interneuron development (Inoue et al., 2002), were not significantly altered by Smo deficiency (Fig. 4D-I).

We next used real-time PCR to quantify transcript levels of various bHLH genes expressed in the retina. In $\mathrm{Smo}^{-1-} \mathrm{cKO}$ retinas, Math5 showed the most augmented expression to 1.5fold of the $\mathrm{Smo}^{+/+}$control retinas (Fig. $4 \mathrm{~J}$ ). In addition, transcripts of the proneural gene $\mathrm{Ngn} 2$ increased by 1.2-fold (Fig. $4 \mathrm{~J}$ ). In contrast, bHLH gene Olig2 and Mash1, which are expressed by progenitor cells (Nakamura et al., 2006; Shibasaki et al., 2007; Ohsawa and Kageyama, 2008), showed 56.2 and 41.8\% reduction, respectively. Other bHLH genes NeuroD and Math3 also showed milder yet substantial reductions. Interestingly, expression of the bHLH transcription repressor Hes1 was reduced by $34.8 \%$ in $\mathrm{Smo}^{-1-}$ cKO mutant retinas at E15.5, whereas Hes5 was not significantly affected by $S m o$ defects (Fig. $4 J$ ). These results indicate that Smo deficiency differentially affects the expression of bHLH transcription factors, especially resulting in significant and sustained upregulation of Math5 expression.

Previous studies have shown that a Pax6-null mutation abolishes the expression of multiple bHLH genes in the retina (Marquardt et al., 2001). Recently, Pax6 was shown to positively regulate Math5 transcription (Riesenberg et al., 2009). We therefore examined whether Smo deficiency affected known homeobox genes expressed by retinal progenitors. Real-time PCR detected a $39.0 \%$ reduction of $R x /$ rax and a $25.9 \%$ decrease of Six3 transcripts, respectively (Fig. $4 \mathrm{~K}$ ). However, total Pax6 expression level in Smo cKO retinas remained similar to the control retinas
(Fig. $4 \mathrm{~K}$ ), suggesting that homeobox genes other than Pax6 were more sensitive to Hh signals.

Hh signaling affects cell cycle distribution of progenitor cells The reduction of the ventricular zone in $\mathrm{Smo}^{-1-} \mathrm{cKO}$ mutant retinas at $\mathrm{P} 0$ (Fig. 1) suggested that $\mathrm{Hh}$ signaling played a critical role in controlling embryonic retinal proliferation, even though loss of Smo function did not completely abolish cell division. For example, at E16.5 despite an obviously reduced ventricular zone Smo cKO mutant retinas continued to incorporate BrdU among progenitor cells (Fig. $5 A-D$ ). To define specific defects caused by Smo deficiency, we examined the distribution of retinal cells during the cell cycle using flow cytometry-based DNA content analysis. Compared with $S m o^{+/-}$retinas, total cell populations from $\mathrm{Smo}^{-1-}$ cKO mutants showed an increase in $\mathrm{G}_{1} / \mathrm{G}_{0}$ and a decrease in S-phase cells at E14.5 (supplemental Fig. 3A, available at www.jneurosci.org as supplemental material). Similar trends were detected at E17.5, when $\mathrm{Smo}^{+/+}$and $\mathrm{Smo}^{+/-}$cells behaved identically, but $S m o^{-1-}$ mutant cells showed an increased distribution in the $G_{0} / G_{1}$ phase and concomitant decreases in both $S$ and $\mathrm{G}_{2} / \mathrm{M}$ phases (supplemental Fig. $3 B$, available at www.jneurosci.org as supplemental material).

To directly analyze the effect of Hh signaling on proliferating progenitor cells, which express high levels of GFP, we next assayed the cell cycle distribution of GFP-positive cells in Smo ${ }^{-1-}$ cKO mutant and heterozygous $S m o^{+/-}$retinas. Profiling GFP intensity and DNA contents at E17.5 clearly showed that Smo ${ }^{-1-}$ 

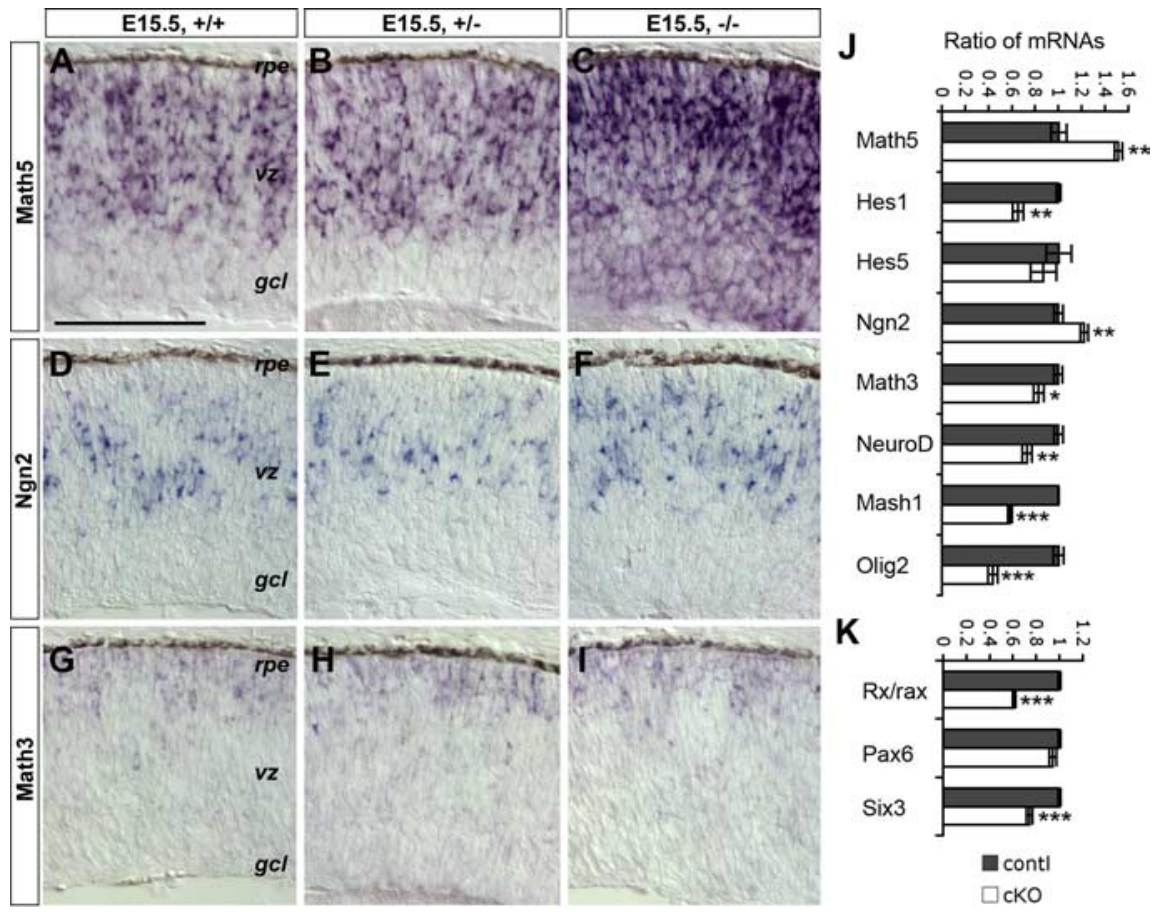

Figure 4. Effects of Smo deficiency on expression of bHLH and homeobox genes in the retina. $A-I$, In situ hybridization analysis of expression patterns for bHLH genes at E15.5. Retinal sections of control $(+/+)(\boldsymbol{A}, \boldsymbol{D}, \boldsymbol{G})$, Smo heterozygote $(+/-)(\boldsymbol{B}, \boldsymbol{E}, \boldsymbol{H})$, and Smo CKO mutant $(-\boldsymbol{I}-)(\boldsymbol{C}, \boldsymbol{F}, \boldsymbol{I})$ were hybridized with antisense probes of Math5 $(\boldsymbol{A}-\boldsymbol{C}), \operatorname{Ngn} 2(\boldsymbol{D}-\boldsymbol{F})$, and $M a t h 3(\boldsymbol{G}-\boldsymbol{I})$. gcl, Ganglion cell layer; rpe, retinal pigment epithelium; $v z$, ventricular zone. Scale bar: (in $\boldsymbol{A}) \boldsymbol{A}-\boldsymbol{I}, 100 \mu \mathrm{m}$. J, $\boldsymbol{K}$, Real-time PCR quantification of transcript levels for bHLH $(\boldsymbol{J})$ and homeobox $(\boldsymbol{K})$ genes expressed in E15.5 retinas. Relative transcript levels are presented as ratios of Smo cKO mutants $(-/-)$ versus Smo controls $(+/+)$ normalized according to $18 \mathrm{~S}$ rRNA $(n=3)$. ${ }^{*} p<$ $0.05,{ }^{* *} p<0.01$, and ${ }^{* * *} p<0.001$. Error bars indicate SEM.

cKO retinas contained more GFP-negative cells with 2n DNA content, indicating the presence of more postmitotic cells in the $\mathrm{G}_{0}$ phase (Fig. $5 E$ ). In contrast, $S m o^{+/-}$retinas contained more GFP-positive cells with 2n DNA content, representing progenitor cells residing in the $\mathrm{G}_{1}$ phase of the cell cycle (Fig. $5 E$ ). Quantification of GFP-positive cells at E14.5 demonstrated that, compared with $S m o^{+1-}$ retinas, $S m o^{-1-} \mathrm{cKO}$ retinas showed a small but significant increase of $\mathrm{G}_{1}$-phase cells $(68.2-71.8 \%)$ and a decrease of S-phase cells (from 21.9 to $18.8 \%$ ) (Fig. $5 F$ ). The cell cycle abnormality became more severe by E17.5; $\mathrm{Smo}^{-1-}$ cKO progenitors showed expanded $\mathrm{G}_{1}$ cell population $(62.6-72.1 \%)$ as well as reduced $S(27.3-20.3 \%)$ and $\mathrm{G}_{2} / \mathrm{M}(10.1-8.4 \%$ ) cell pools (Fig. $5 G$ ). These results demonstrate that Hh signals profoundly affect cell cycle distribution of proliferating progenitor cells. Moreover, the effect of $\mathrm{Hh}$ signaling on the cell cycle is greater to late embryonic retinal progenitors.

\section{Hh signals regulate cell cycle progression}

To investigate whether the abnormal cell cycle distribution of Smo-deficient progenitor cells was caused by defects in cell cycle progression, we examined expression of cell cycle regulators. By in situ hybridization, we detected very low expression of the Gli1 gene in the ventricular zone of $\mathrm{Smo}^{-1-} \mathrm{CKO}$ mutant retinas at E15.5, indicating a successful blockade of Hh signaling to retinal progenitors (Fig. $6 A, B$ ). Interestingly, the expression level of Shh gene was not upregulated in $S m o^{-1-}$ cKO mutant, despite increased RGCs (Fig. 6E). In situ hybridization revealed that $\mathrm{Smo}^{-1-}$ cKO retinas contained fewer cells expressing cyclin D1, a major $G_{1}$-phase cyclin, in the ventricular zone as well as markedly reduced levels of cyclin D1 transcript in cells still expressing this gene (Fig. 6C,D). This result was confirmed by real-time PCR that detected severe reduction of cyclin D1 transcript by $70.9 \%$ (Fig. $6 E$ ). In addition, cyclin $E$, a late $G_{1}$-phase cyclin critical for the reentry of $S$ phase, showed $>53.3 \%$ decrease compared with $\mathrm{Smo}^{+/+}$controls (Fig. 6E). In addition, cyclin $A 2$, cyclin $B 1$, and cyclin D3 also showed decreased expression (Fig. $6 E$ ). Furthermore, expression of the transcription factor $E 2 F 1$, which is required for the $\mathrm{G}_{1}$-to-S transition in a phosphorylationdependent manner, showed $29.3 \%$ reduction (Fig. 6E). Analyses by flow cytometry also validated that cyclin D1-positive cells were decreased in $\mathrm{Smo}^{-1-} \mathrm{cKO}$ mutants compared with the Smo ${ }^{+/+}$control (47.9$32.7 \%$ ) (Fig. 6F). Concomitantly, Smo ${ }^{-1-}$ $\mathrm{cKO}$ retinas contained increased number of cyclin-dependent kinase (CDK) inhibitor p27 ${ }^{\text {Kip1 }}$-positive cells compared with $\mathrm{Smo}^{+/+}$controls $(47.8-63.5 \%)$. In contrast, the number of cells expressing another CDK inhibitor, p57 ${ }^{\text {Kip } 2}$, did not change (Fig. $6 F$ ).

To further define the defective step in cell cycle progression caused by Smo deficiency, we performed BrdU pulse-chase coupled with DNA content analysis, which allowed us to monitor a cohort of progenitor cells as they emerged from the $S$ phase and progressed through the cell cycle. In E16.5 wild-type retinas, immediately after a 30 min BrdU labeling, 100\% of the BrdU-labeled cells resided in the $\mathrm{S}$ phase (Fig. $6 G$ ). As the chasing period lengthened, BrdUpositive $S$-phase cells gradually declined, coinciding with the emergence of BrdU-labeled $G_{2} / M$ and $G_{1} / G_{0}$ phase cells. At $9 \mathrm{~h}$ after the BrdU pulse, $\sim 67 \%$ of the BrdU-labeled cells were in $\mathrm{G}_{1} / \mathrm{G}_{0}$ phase and $\sim 25 \%$ were in $\mathrm{G}_{2} / \mathrm{M}$ phase. By $18 \mathrm{~h}$ after BrdU labeling, coinciding with the $G_{1} / G_{0}$ population decline, the BrdU-labeled cells were once again reentering $S$ phase of the cell cycle (Fig. 6G). We performed similar analyses to examine cell cycle progression of $\mathrm{Smo}^{-1-}$ mutant cells at 9 and $18 \mathrm{~h}$ after BrdU pulse labeling at E17.5. At $9 \mathrm{~h}$ after labeling, we detected no difference in $\mathrm{S}$ and $\mathrm{G}_{2} / \mathrm{M}$ phase distributions between $S m o^{+/-}$heterozygous and $\mathrm{Smo}^{-1-} \mathrm{CKO}$ mutant cells, indicating that the $\mathrm{S}$ to $\mathrm{G}_{2} / \mathrm{M}$ transition was mostly unaffected (Fig. $6 \mathrm{H}$ ). However, by $18 \mathrm{~h}$, among BrdU-labeled cells, more mutant cells accumulated in the $G_{1} / G_{0}$ phase $(60.4-68.1 \%)$, and fewer cells had reentered $S$ phase (38.1-29.6\%), suggesting a $G_{1} / S$ transition defect (Fig. $6 H$ ). Importantly, we also analyzed GFP and BrdU doublepositive cells, which represented the progenitor cell population excluding postmitotic cells, at $18 \mathrm{~h}$ after BrdU labeling, and obtained similar results (supplemental Fig. 4, available at www. jneurosci.org as supplemental material). Together, these data indicate that Hh signaling critically affects retinal progenitor cell proliferation by facilitating $\mathrm{G}_{1} / \mathrm{S}$ phase transition.

\section{Math5 plays a key role in mediating effects of Hh signaling on neuronal fates}

To delineate the relationship between increased Math5 expression and enhanced RGC production found in the $S m o^{-1-}$ cKO mutants, we generated Smo and Math5 double-mutant retinas. 


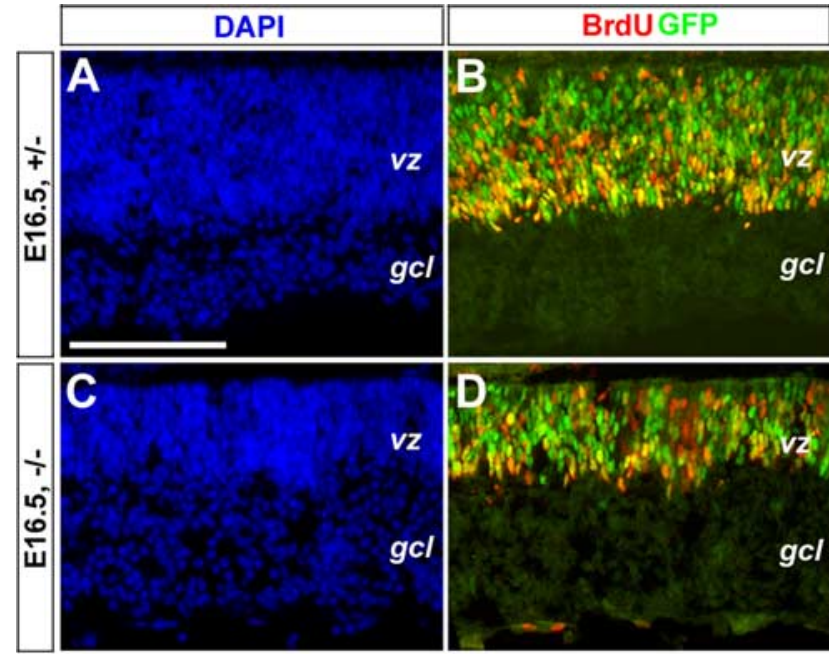

$\mathbf{F}$
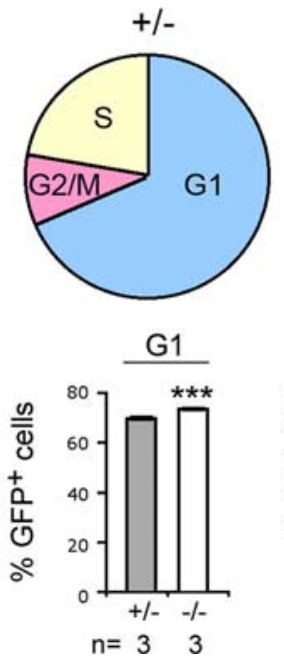

E14.5

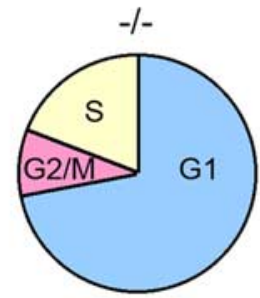

S

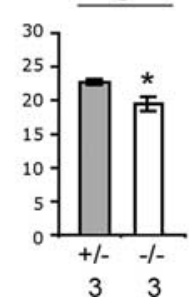

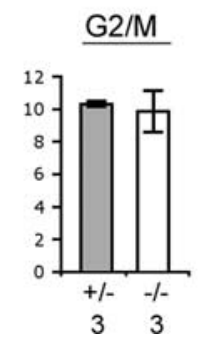

E

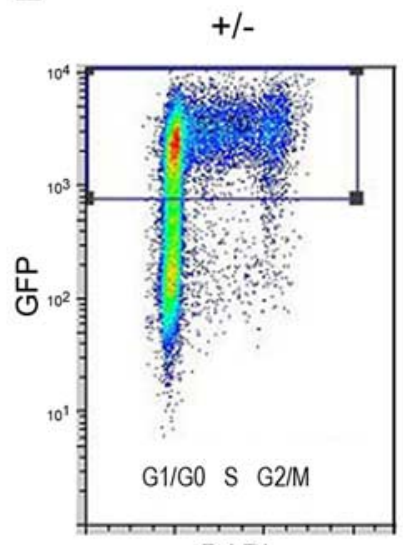

DAPI

G

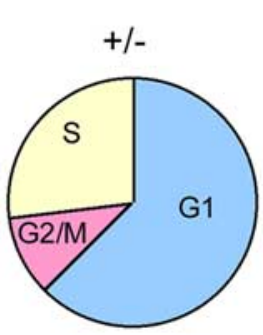

E17.5
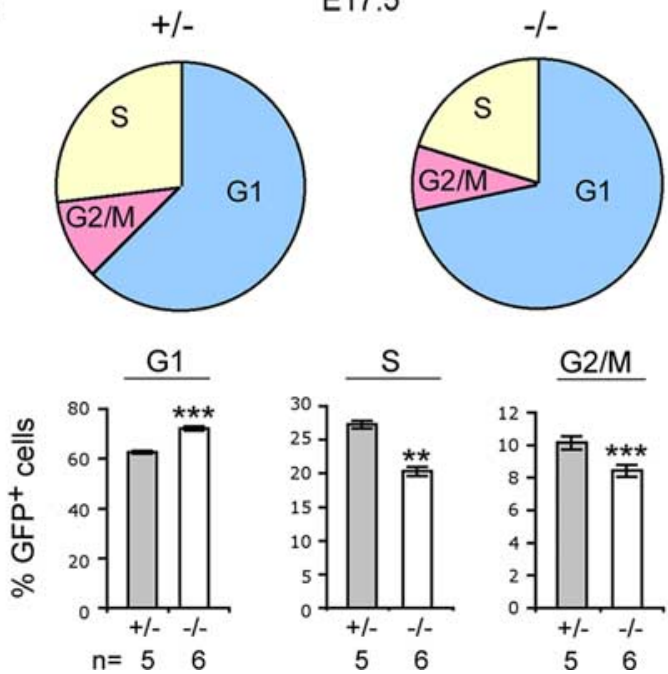

E17.5

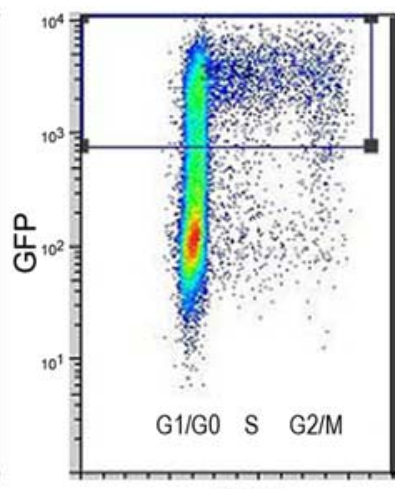

DAPI
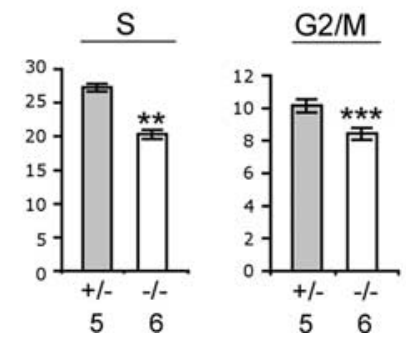

Figure 5. Altered progenitor cell cycle distribution in Smo mutant retinas. $\boldsymbol{A}-\boldsymbol{D}$, Immunofluorescent labeling for progenitor cells at E16.5. Retinal sections derived from Smo heterozygous $(+/-)(\boldsymbol{A}, \boldsymbol{B})$ and Smo cKO mutant $(-/-)(\boldsymbol{C}, \boldsymbol{D})$ retinas were colabeled with DAPI $(\boldsymbol{A}, \boldsymbol{C})$, BrdU (red) and GFP (green) (merged in $\boldsymbol{B}, \boldsymbol{D})$. gcl, Ganglion cell layer; $v z$, ventricular zone. Scale bar: (in $\boldsymbol{A}) \boldsymbol{A}-\boldsymbol{D}, 100 \mu \mathrm{m}$. $\boldsymbol{E}$, Flow cytometry profiles of Smo heterozygous (+/ - ) and Smo cKO mutant $(-/-$ ) retinal cells at E17.5 according to GFP labeling intensity ( $y$-axis) and DNA content as indicated by DAPI labeling ( $x$-axis). The gated areas indicate GFP-positive cells used for cell cycle distribution analyses shown in $\mathbf{G}$. $\boldsymbol{F}, \boldsymbol{G}$, Flow cytometric analyses of cell cycle distribution of GFP-positive progenitor cells at E14.5 (F) and E17.5 (G). GFP-positive cells of Smo heterozygous (+/ -$)$ and Smo cK0 mutant $(-/-)$ retinas from boxed regions in $\boldsymbol{F}$ were quantified according to their DNA contents. Percentages of cells in the $G_{1}, G_{2} / M$, and $S$ phases of the cell cycle among total GFP-positive cells are shown as pie charts and bar graphs. Genotypes $(+/+$, Smo flox /flox with no cre; $+1-$, Smo flox/+ with Chx10-cre; $-/-$, Smo flox /flox with Chx10-cre) and numbers ( $n$ ) of individual retinas analyzed are indicated below the bar graphs. ${ }^{*} p<0.05 ;{ }^{* *} p<0.01$, and ${ }^{* *} p<0.001$. Error bars indicate SEM.

The $S m o^{+/-} ;$Math $^{+/-}$double heterozygous retinas showed similar distribution and proportion of RGCs compared with $\mathrm{Smo}^{+/+}$; $\mathrm{Math}^{+/-}$retinas (data not shown), whereas $\mathrm{Smo}{ }^{-/-}$; Math $5^{+/-}$retinas contained an increased number of Brn3apositive RGCs (Fig. 7I,J,Q,T). As previously described in Math $^{-1-}$ KO mutant retinas, the Smo ${ }^{+/-}$; Math $5^{-1-}$ retinas showed a dramatic reduction in RGCs compared with $S m o^{+/-}$; Math $5^{+/-}$retinas (Fig. $7 I, K, Q, T$ ). Quantitative analysis also confirmed that NF145-positive cells were increased in Smo ${ }^{-1-}$; Math $^{+/-}$and decreased in Smo ${ }^{+/-} ;$Math $^{-/-}$retinas compared with the double heterozygous $\mathrm{Smo}{ }^{+/-} ; \mathrm{Math}^{+/-}$controls (Fig. $7 R, T$ ). In Smo ${ }^{-1-} ; M_{\text {ath }} 5^{-1-}$ double mutants, the enhanced RGC production observed in Chx10-Cre-mediated $\mathrm{Smo}^{-1-}$ cKO retinas was completely blocked, and the proportion of RGCs was similar to those found in $\mathrm{Smo}^{+/-} ; \mathrm{Math}^{-/-}$retinas (Fig. 7I-L, Q, R, T). These results demonstrate that the proneural bHLH protein Math5 is necessary for the increased RGC genesis found in $\mathrm{Smo}^{-1-}$ retinas.
We also analyzed effects of Math5 deficiency on cone cell production in the Smo cKO mutant background. The Smo ${ }^{+/-}$; Math $5^{+/-}$double heterozygous retinas showed normally patterns of labeling by the cone cell marker $\mathrm{G} \gamma \mathrm{C}$ as found in Smo ${ }^{+/+}$; Math5 ${ }^{+/-}$retinas (data not shown). Consistent with previous Math5 KO results (Brown et al., 1998), Smo ${ }^{+/-}$; Math $5^{-/-}$retinas displayed slightly enhanced $\mathrm{G} \gamma \mathrm{C}$ labeling at the ventricular surface at E17.5 compared with the Smo ${ }^{+/-}$; Math $5^{+/-}$double heterozygous retinas (Fig. 7 M,O). Quantification further revealed that $\mathrm{Smo}^{-1-} ; \mathrm{Math}^{+/-}$and $\mathrm{Smo}^{+/-}$; Math $5^{-1-}$ retinas also contained statistically significant increases of Crx-positive photoreceptor precursors at E17.5, from the $\mathrm{Smo}^{+/-}$; Math5 $5^{+/-}$double heterozygous level of $17.3-20.3 \%$ and $24.9 \%$, respectively (Fig. $7 S, T$ ). Interestingly, the $S m o^{-1-}$; Math $5^{-1-}$ double mutants showed an additional enhancement of $\mathrm{G} \gamma \mathrm{C}$ labeling at the ventricular surface compared with either Smo or Math 5 single mutants (Fig. 7M-P). Quantitative analyses confirmed that the Smo ${ }^{-1-}$; Math $5^{-1-}$ double KO retinas con- 

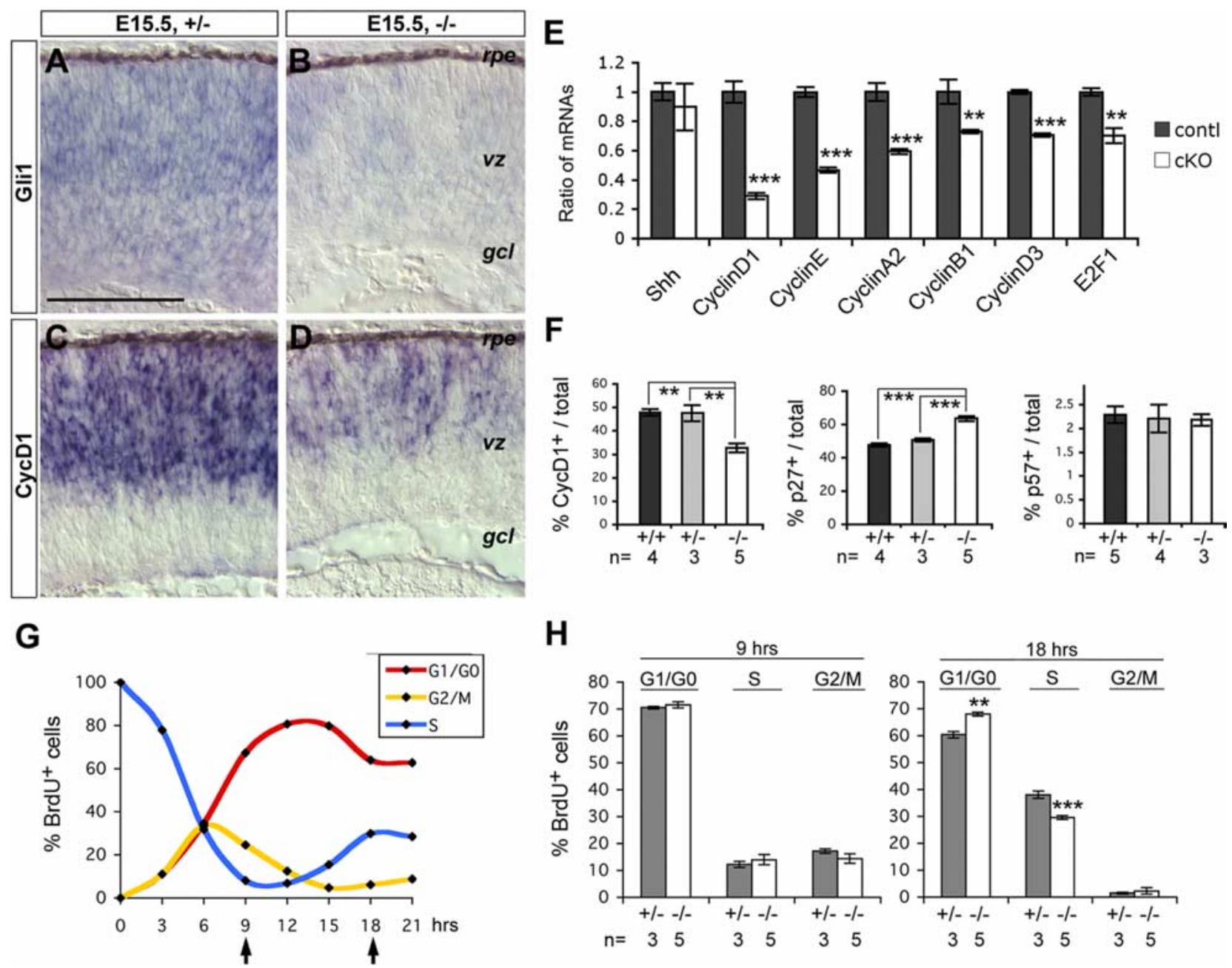

Figure 6. Abnormal cell cycle progression of Smo-deficient retinal progenitors. $\boldsymbol{A}-\boldsymbol{D}$, In situ hybridization analysis for $G$ li1 and cyclin D1 at E15.5. Sections of $S m o$ heterozygotes $(+/-)(\boldsymbol{A}, \boldsymbol{C})$ and Smo cK0 mutant $(-/-)(\boldsymbol{B}, \boldsymbol{D})$ retinas were probed with antisense probes of $G$ li1 $(\boldsymbol{A}, \boldsymbol{B})$ and cyclin D1 $(\boldsymbol{C}, \boldsymbol{D})$. gcl, Ganglion cell layer; rpe, retinal pigment epithelium; $v z$, ventricular zone. Scale bar: (in $A) A-D, 100 \mu \mathrm{m}$. $\boldsymbol{E}$, Real-time PCR quantification of transcript levels for Shh, E2F1, and various cyclins expressed in the retina at E15.5. Relative transcript levels are presented as ratios of $S m o$ cKO $(-/-)$ versus Smo controls $(+/+)$ normalized according to 185 rRNA $(n=3) .{ }^{* *} p<0.01 ; * * * 00.001$. $F$, Quantification of cell cycle regulators by flow cytometry. Percentages of cyclin D1-, p27 ${ }_{\text {Kip1 }}$-, and $557^{\text {Kip2 }}$-positive cells among total cells at E17.5 are shown. G, Graphic illustration of cell cycle progression following a cohort of BrdU-labeled progenitor cells. Wild-type E16.5 retinal explants were labeled with BrdU for 30 min followed by flow cytometric analysis for BrdU-positive cells in various phases of the cell cycle for up to $21 \mathrm{~h}$. $\boldsymbol{H}$, Comparison of cell cycle progression between Smo heterozygous ( $+/-)$ and Smo cK0 mutant $(-/-)$ retinal cells at E17.5. The bar graphs show the distribution of BrdU-positive cells among different phases of the cell cycle at 9 and $18 \mathrm{~h}$ after

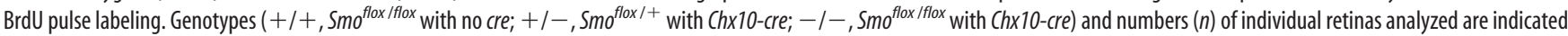
below the bar graphs. ${ }^{* *} p<0.01 ;{ }^{* * *} p<0.001$. Error bars indicate SEM.

tained 27.4\% Crx-positive cells (Fig. 7S,T), indicating that effects on enhanced cone production caused by Smo and Math5 deficiencies were additive.

\section{Effect of $\mathrm{Hh}$ signaling on $\mathrm{G}_{1}$ to $S$ phase transition is independent of Math5}

A previous study has suggested that loss of Math5 function affects the cell cycle exit of early retinal progenitors (Le et al., 2006); we therefore examined whether Math5 played a role in the cell cycle defects detected in Smo mutant retinas. Immunostaining of GFP at E17.5 revealed that, in contrast to the $\mathrm{Smo}^{-1-}$; Math5 ${ }^{+/-}$ retinas, $\mathrm{Smo}^{+1-}$; $\mathrm{Math}^{-1-}$ and $\mathrm{Smo}^{-1-}$; Math5 ${ }^{-1-}$ retinas retained a broad ventricular zone occupied by GFP-positive cells (Fig. $7 E-H$ ). However, compared with heterozygous $\mathrm{Smo}^{+/-}$; Math5 ${ }^{+/-}$retinas, $\mathrm{Smo}^{-1-}$; Math5 ${ }^{+/-}$retinas contained onehalf of the GFP-positive progenitor cells (51.9-25.4\%), whereas $\mathrm{Smo}^{+1-}$; Math $5^{-1-}$ retinas showed a lesser but statistically significant reduction of the progenitor pool (51.9-42.5\%) (Fig.
$8 \mathrm{~A}, \mathrm{C})$. The Smo ${ }^{-1-}$; Math5 $5^{-1-}$ double $\mathrm{KO}$ retinas did not show additional loss of GFP-positive progenitors compared with $\mathrm{Smo}^{-1-} ; \mathrm{Math}^{+/-}$retinas (Fig. $8 \mathrm{~A}, \mathrm{C}$ ).

To examine the potential effects of Math5 on cell cycle progression, we analyzed the distribution of GFP-positive progenitors in different phases of the cell cycle. As expected, the GFPpositive progenitors in the $\mathrm{Smo}^{-1-}$; $\mathrm{Math}^{+-}$retinas consistently showed a significantly higher percentage of $\mathrm{G}_{1}$ cells (from 65.6 to $76.1 \%$ ) and lower percentage of $S$ phase cells (from 29.8 to $20.3 \%$ ) compared with heterozygous $\mathrm{Smo}^{+/-}$; $\mathrm{Math}^{+/-}$ retinas (Fig. 8B,C). However, loss of Math 5 in $\mathrm{Smo}^{+/-}$; Math $5^{-I-}$ retinas only resulted in slight decline of S-phase cells $(29.8-26.7 \%)$ and no changes in $\mathrm{G}_{1}$ or $\mathrm{G}_{2} / \mathrm{M}$ distribution (Fig. $8 B, C)$. Moreover, the Smo ${ }^{-1-}$; Math5 ${ }^{-1-}$ double KO retinas showed similar cell cycle distribution as found in the Smo singlemutant $\mathrm{Smo}^{-1-}$; Math5 ${ }^{+/-}$retinas (Fig. 8B,C). These results indicate that Math 5 function does not impact on the $G_{1}$ to $S$ phase transition normally promoted by $\mathrm{Hh}$ signaling. 


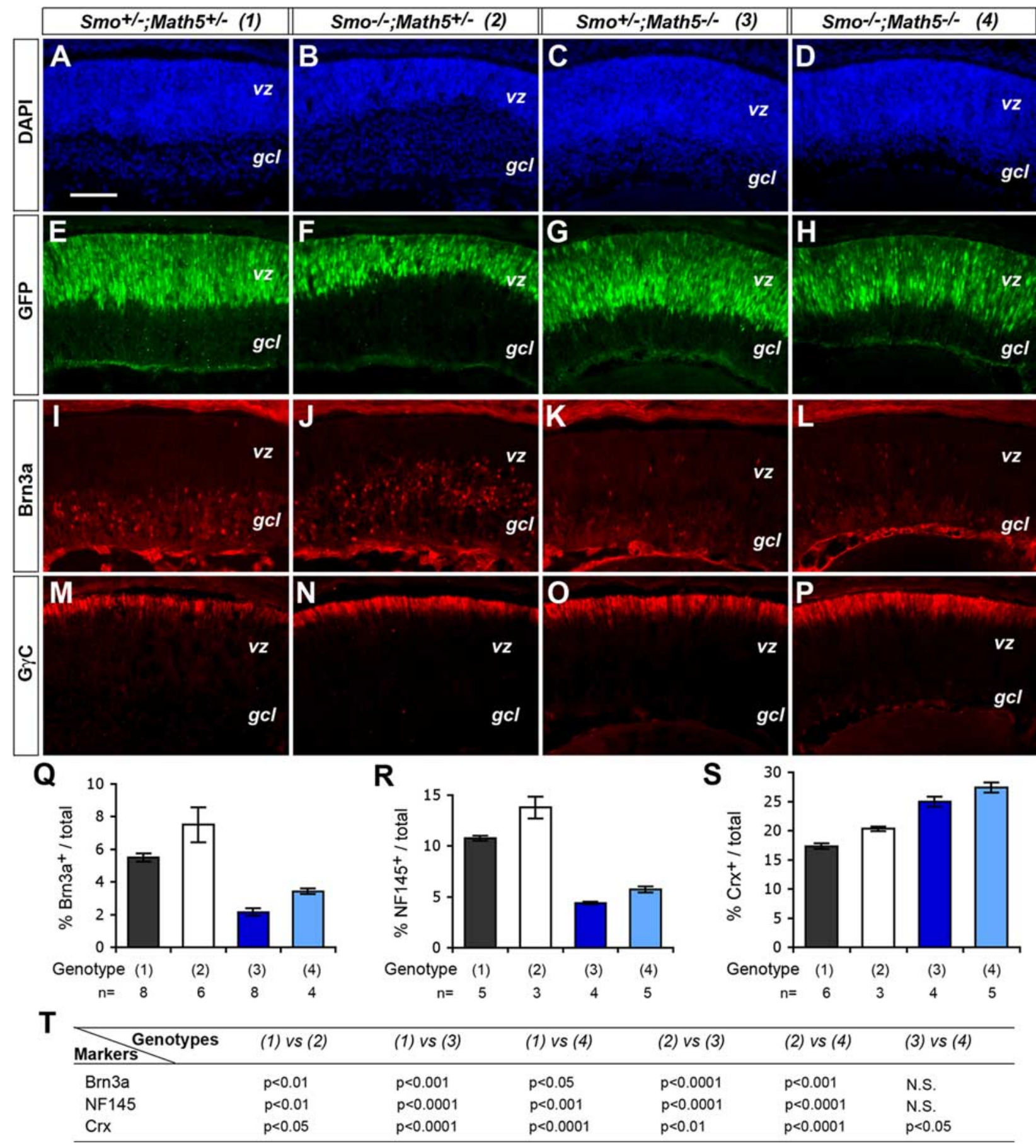

Figure 7. Effects of $S m o$ and Math 5 double mutations on RGC and cone cell production. $\boldsymbol{A}-\boldsymbol{P}$, Immunofluorescent labeling of cell markers in control and different mutant retinas at E17.5. Sections

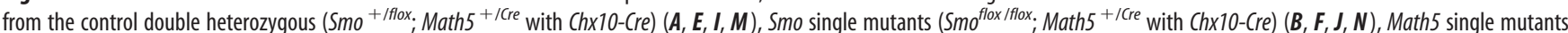

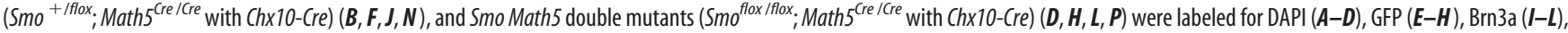
and $G \gamma C(\boldsymbol{M}-\boldsymbol{P})$. gcl, Ganglion cell layer; $v z$, ventricular zone. Scale bar: (in $\boldsymbol{A}) \boldsymbol{A}-\boldsymbol{P}, 100 \mu \mathrm{m}$. Q- $\boldsymbol{T}$, Quantification of RGC and photoreceptor marker-positive cells by flow cytometry in single- and double-mutant retinas at E17.5. Q-S, Bar graphs show percentages of marker-positive cells among total cells. Genotypes of the retinas are (1) double heterozygous (Smo + /flox; Math5 ${ }^{+/ / \text {cre }}$ with

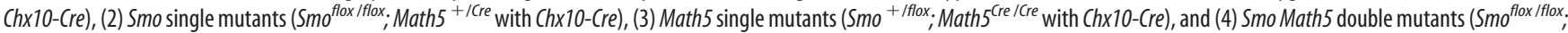
Math $5^{\text {(re } /(r e ~}$ with $(h \times 10-(r e)$. The numbers ( $n$ ) of individual retinas analyzed are indicated below the bar graphs. $T$, A table lists $p$ values for different markers according to statistical analyses among various genotypes. N.S., Not significant. Error bars indicate SEM.

\section{Discussion}

Previous studies of Hh function in vertebrate retinas have mostly relied on perturbation of ligands by genetic and nongenetic means, which often result in partial elimination of $\mathrm{Hh}$ signals and variable phenotypes. In this study, by ablating the essential Hh signaling component Smo, we have achieved a total blockade of $\mathrm{Hh}$ signaling in individual Smo mutant cells. Using the Chx10-Cre driver, we show that $\mathrm{Hh}$ signaling is required by progenitors in a cell-autonomous manner. Comparing the phenotypes of Smo knock-out by Chx10$\mathrm{Cre}$ in cycling progenitors and by Math5-Cre in progenitors exiting the cell cycle, we conclude that $\mathrm{Hh}$ signaling is required by progenitor cells before their terminal mitosis to generate neurons. 

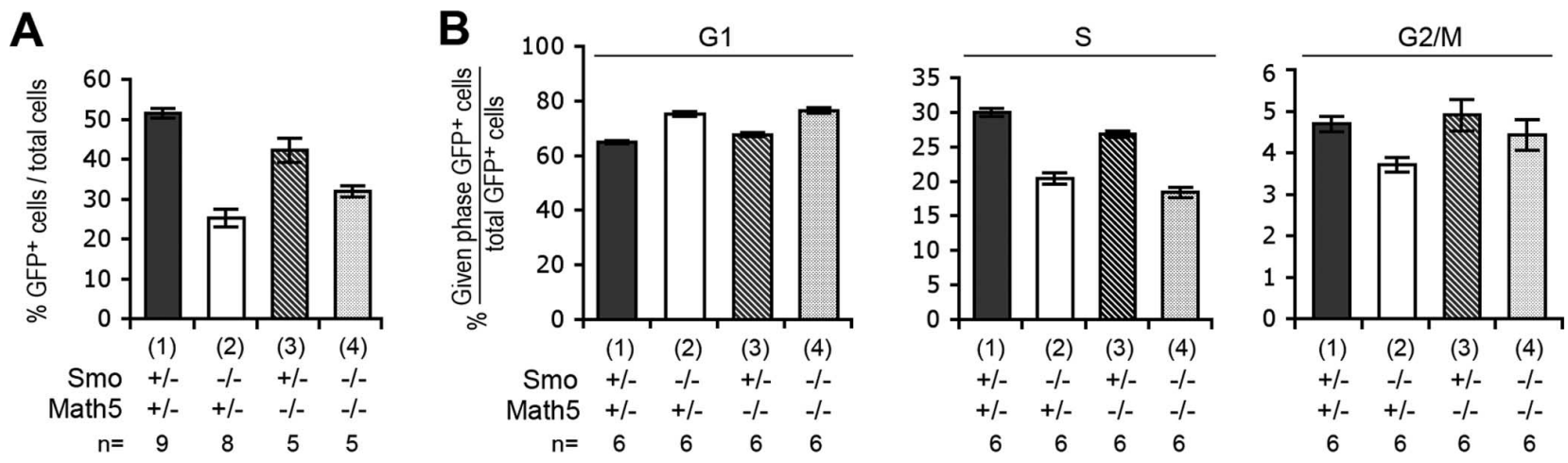

\begin{tabular}{|c|c|c|c|c|c|c|}
\hline $\begin{array}{l}\text { Genotypes } \\
\text { Cell Types }\end{array}$ & (1) vs (2) & (1) vs (3) & (1) vs (4) & (2) vs (3) & (2) vs (4) & (3) vs (4) \\
\hline $\mathrm{GFP}+/$ total cells & $p<0.0001$ & $p<0.05$ & $p<0.0001$ & $p<0.001$ & N.S. & $p<0.05$ \\
\hline $\begin{array}{l}\text { G1 phase GFP+ } \\
\text { S phase GFP+ } \\
\text { G2M phase GFP+ }\end{array}$ & $\begin{array}{l}p<0.0001 \\
p<0.0001\end{array}$ & $\begin{array}{l}\text { N.S. } \\
\mathrm{p}<0.05\end{array}$ & $\begin{array}{l}p<0.0001 \\
p<0.0001\end{array}$ & $\begin{array}{l}p<0.001 \\
p<0.0001\end{array}$ & N.S. & $\begin{array}{l}p<0.0001 \\
p<0.0001\end{array}$ \\
\hline
\end{tabular}

Figure 8. Effects of Smo and Math5 double mutation on progenitor cell expansion and cell cycle regulation. $\boldsymbol{A}$, Quantification of GFP-positive cells by flow cytometry in single- and double-mutant retinas at E17.5. Percentages of GFP-positive cells among total cells are shown. $\boldsymbol{B}$, Flow cytometric analyses of progenitor cell distribution in different phases of the cell cycle. Percentages of GFP-positive cells in the $G_{1}, S$, and $G_{2} / M$ phases of the cell cycle among total GFP-positive cells are shown as bar graphs. The numbers ( $n$ ) of individual retinas and their genotypes are indicated below the bar graphs. Error bars indicate SEM. C, A table lists $p$ values for comparisons among various genotypes for proportions of progenitor cells and cell cycle phase distribution. N.S., Not significant.

The Chx10-Cre-mediated Smo deletion results in severe reduction of progenitors and altered neuronal composition by birth. Therefore, we focused our phenotypic analyses on the embryonic retina to avoid confounding cumulative mutational effects. The most noticeable phenotype is the dramatic increase of RGCs in Chx10-cre-mediated Smo cKO retinas. However, despite the expression of Brn3a in the overproduced RGCs ( $\mathrm{Mu}$ et al., 2008), these neurons may not be fully mature as they have persistent Math5 but abnormally low levels of Shh expression. In addition, photoreceptor precursors showed a mild yet statistically significant increase in Smo cKO retinas. In contrast to altered RGCs and cone cells, we did not detect significant changes in AP2 $\alpha$-positive amacrine cells, Lim1-positive horizontal cells, or calbindin-positive horizontal and amacrine cells. This is consistent with our result that Smo deficiency did not affect p57 ${ }^{\mathrm{Kip} 2}$, which marks calbindin-positive amacrine cells (Dyer and Cepko, 2001a,b,c). Therefore, in the mouse retina Hh signals profoundly influence the fate determination of a subset of early-born neurons, primarily RGCs and cone photoreceptors.

The enhanced RGC genesis in Smo mutant retinas provides compelling genetic evidence that signals derived from postmitotic neurons greatly influence uncommitted progenitors (Zhang and Yang, 2001; Kim et al., 2005; Hashimoto et al., 2006). Among various homeobox and bHLH genes implicated in retinogenesis (Ohsawa and Kageyama, 2008), Hh signaling preferentially suppresses Math5, a key proneural gene required for RGC specification (Brown et al., 2001; Wang et al., 2001). Our results suggest that Hh signals either directly or indirectly regulate Math5 expression. One possibility is that downstream Hh signaling effectors, the Gli proteins, are directly involved in suppressing Math5 expression in $\mathrm{Hh}$ responsive progenitor cells. Alternatively, $\mathrm{Hh}$ signaling can activate transcription repressor(s) that in turn suppress Math5 transcription. In Smo cKO mutant retinas, expression of the transcription repressor Hes1 is significantly reduced, indicating that $\mathrm{Hh}$ signaling positively regulates $\mathrm{Hes} 1$, which suppresses proneural genes (Matter-Sadzinski et al., 2005; Kageyama et al., 2007). Hes1 is a known effector for Notch signaling, which has been shown to inhibit RGC and cone photoreceptor genesis (Austin et al., 1995; Dorsky et al., 1995, 1997; Ahmad et al., 1997; Jadhav et al., 2006; Yaron et al., 2006). Interestingly, we have shown that VEGF (vascular endothelial growth factor), another RGC-secreted factor that promotes progenitor proliferation and suppresses RGC production, also engages Hes 1 activity to regulate RGC genesis independent of Notch and ERK (extracellular signal-regulated kinase) (Hashimoto et al., 2006). Thus, a plausible hypothesis is that Hh signals positively stimulate Hes 1 expression in progenitor cells, which in turn downregulates Math5 to suppress the RGC fate (Hashimoto et al., 2006) (Fig. 9). Consistent with this hypothesis, a recent study shows that Gli2 may directly promote Hes 1 transcription in the postnatal retina (Wall et al., 2009). During cortical neurogenesis, dynamic Hes1 oscillation regulates proneural gene $\mathrm{Ngn} 2$ in progenitors (Shimojo et al., 2008). We have detected an increase of Ngn2 in the Smo cKO retinas, suggesting that Hes1 may similarly suppress $\mathrm{Ngn} 2$ during retinogenesis. Expression of Math5 normally occurs among embryonic retinal progenitors and is under stringent controls (Hutcheson et al., 2005; Hufnagel et al., 2007; Willardsen et al., 2009), including positive regulation by Pax6 through the $5^{\prime}$ enhancers (Riesenberg et al., 2009). However, the total Pax6 expression level is not affected by Smo deficiency, suggesting that the loss of suppression is responsible for Math5 upregulation. Together, our results demonstrate that $\mathrm{Hh}$ is a major negative regulator of Math5, but the precise mechanism of Hh suppression on this proneural gene requires additional analysis at the molecular level.

In addition to giving rise to RGCs, Math5-expressing progenitors also contribute to other retinal cell types, including cones (Yang et al., 2003). In Math5 mutants, abnormal cone photoreceptors have been detected (Brown et al., 2001; Le et al., 2006). Our analyses show that the Math5 single mutant contains a higher proportion of photoreceptor precursors than the Smo single mutant; and that the effects of Smo and Math5 mutations on 


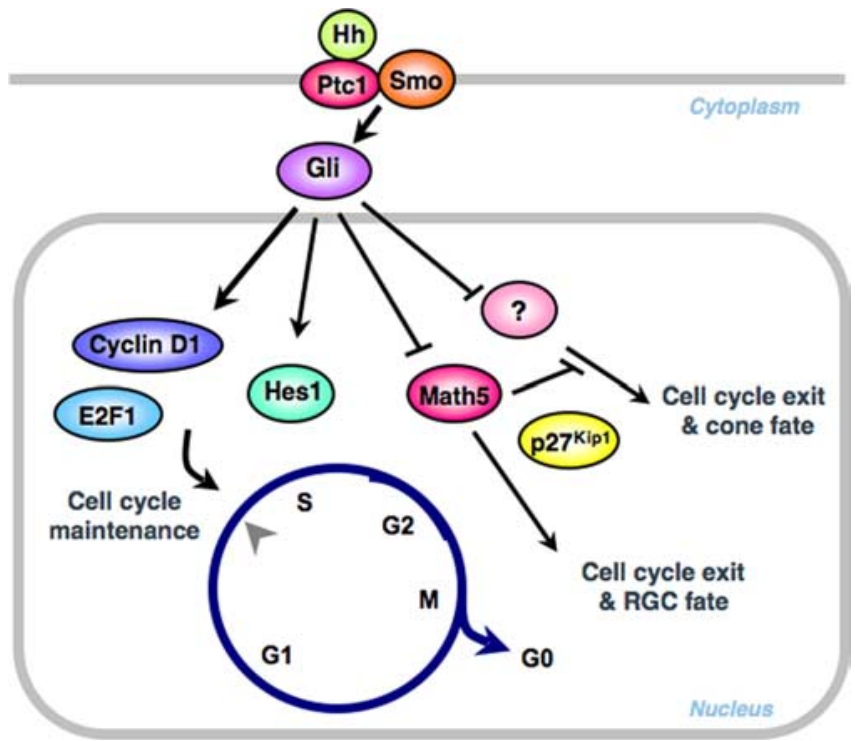

Figure 9. Hh signaling effects in neurogenic retinal progenitors. A proposed model illustrates the distinct Hh signaling effects in uncommitted neural progenitors. On receiving Hh signals, Gli effectors directly or indirectly enhance the expression of $G_{1}$-phase cyclins including cyclin $D 1$ and cyclin $E$ to promote $G_{1}$ to $S$ phase transition. Hh signals may also facilitate $G_{2} / M$ progression by upregulating cyclin $A$ and/or cyclin $B$ (data not shown). The Hh effect on cell cycle progression occurs in all proliferating progenitors in the embryonic retina. In addition, Hh-triggered Gli activation directly or indirectly suppresses the bHLH factor Math5 and other proneural gene(s), which cooperate with specific CDK inhibitors such as $p 27^{\text {Kip1 } 1}$ to facilitate cell cycle exit and specify RGC or cone cell fate. Hh signaling also promotes expression of Hes 1 , which may participate in cell cycle regulation and/or proneural gene suppression. Hh signaling affects cell cycle withdrawal and neuronal fate choice by impacting the dynamics of proneural gene expression during the neurogenic cell cycle when one or two postmitotic neurons are produced.

Crx-positive cells are additive in the double mutants. Thus, Smo and Math5 may independently contribute to cone suppression, possibly by stimulating Hes1 and repressing other bHLH proteins. Moreover, other factors that promote cell cycle exit and the photoreceptor fate may become more available in Smo and Math5 double mutants (Fig. 9). Unlike Math5 and Ngn2, expression levels of several bHLH genes are reduced in the Smo mutant, suggesting that Hh signals normally promote these factors. However, because of the complex relationships among the bHLH proteins, additional studies are necessary to delineate how they are influenced by $\mathrm{Hh}$.

Hh signals promote progenitor proliferation in the developing CNS (Kenney and Rowitch, 2000; Ruiz i Altaba et al., 2002; Kenney et al., 2003, 2004; Cayuso et al., 2006). However, the role of $\mathrm{Hh}$ signals in vertebrate retinal proliferation has remained controversial (Agathocleous et al., 2007). In rodent retinal cultures, Shh-N has a mitogenic effect (Jensen and Wallace, 1997; Levine et al., 1997). But in zebrafish, Shh appears to upregulate p57 ${ }^{\text {Kip2 }}$ and facilitate cell cycle exit (Shkumatava and Neumann, 2005). In the Xenopus retina, elevated Hh signals appear to accelerate cell cycle progression through both $\mathrm{G}_{1} / \mathrm{S}$ and $\mathrm{G}_{2} / \mathrm{M}$ transitions and that fast cycling progenitors have a higher tendency to exit the cell cycle (Locker et al., 2006). In this study, we demonstrate that Smo deficiency causes delayed S phase reentry, thus resulting in the accumulation of $G_{1}$ phase and reduction of $S$ phase cells. Interestingly, both E14.5 and E17.5 progenitors have the same distribution in the $\mathrm{G}_{2} / \mathrm{M}$ phase $(\sim 10 \%)$, but a higher proportion of E17.5 progenitors are in the $S$ phase compared with E14.5 (27 vs 23\%). The more severe defects found in E17.5 pro- genitors may reflect the higher rate of S-phase reentry in the late embryonic retina. Our quantitative analyses demonstrate that Smo deficiency causes severe reduction of the $G_{1}$-phase cyclins, cyclin D1 and cyclin E, which critically control the checkpoint in $\mathrm{G}_{1}$ (Dehay and Kennedy, 2007). We also detected reduced expression of $\mathrm{G}_{2} / \mathrm{M}$ cyclins, cyclin $\mathrm{A} 2$ and cyclin $\mathrm{B} 1$, which is consistent with the observed decrease of $\mathrm{G}_{2} / \mathrm{M}$ phase cells at E17.5. Results presented here thus provide definitive genetic evidence that Hh signals play an important role in embryonic mouse retinal proliferation.

A fundamental question concerning cell fate determination is whether cell proliferation is intimately linked to cell fate commitment or whether they are controlled separately. Some recent studies suggest that cell cycle regulation and cell fate specification can be uncoupled (Godinho et al., 2007; Ajioka et al., 2007; Rompani and Cepko, 2008). One interpretation of Smo cKO mutant phenotypes is that the absence of Hh signaling causes premature cell cycle withdrawal and consequently enhanced neurogenesis. Contrary to this, our findings show that Smo deficiency preferentially affects a subset, instead of all early-born cell types, unlike what happens when the cell cycle is completely blocked (Harris and Hartenstein, 1991). Moreover, Hh signals differentially influence the expression of proneural genes, which are involved in specifying distinct retinal cell fates (Ohsawa and Kageyama, 2008). The selective influence of Hh on neuronal fates suggests that separate intracellular machineries are involved in regulating cell cycle progression and cell fate choices.

How might Hh signals coordinate cell proliferation and cell fate selection? Based on current data, we favor a model in which Hh signals impact the cell cycle machinery in all progenitors, but critically influence the fate specification only in cells in their neurogenic cell cycle, during which at least one postmitotic neuron is generated. Because Math 5 is detectable in a subset of progenitor cells in $\mathrm{G}_{2} / \mathrm{M}$ phase, it is plausible that Hh signals impact cell fate before and/or during $\mathrm{G}_{2} / \mathrm{M}$ through modulation of Math5 (Fig. 9). A recent study indicates that Math5 also affects cell cycle exit (Le et al., 2006). Our analyses of Smo and Math5 double mutants suggest that Math 5 is involved in mediating the effects of $\mathrm{Hh}$ on RGC genesis but not on cell cycle progression. Accumulating evidence suggests that bHLH proteins regulate the Cip/Kip family of CDK inhibitors (Guo et al., 1995; Halevy et al., 1995; Georgia et al., 2006; Rothschild et al., 2006; Buttitta and Edgar, 2007; Sukhanova et al., 2007). Thus, Math5 is likely to promote cell cycle exit by cooperating with $\mathrm{p} 27^{\mathrm{Kip} 1}$ and specify the RGC fate during the terminal mitosis (Fig. 9).

In summary, our molecular genetic study indicates that $\mathrm{Hh}$ signals affect both progenitor cell proliferation and cell fate commitment. Our results support that Hh signals promote cell cycle progression during $\mathrm{G}_{1} / \mathrm{S}$ transition and regulate specific proneural gene(s) during $\mathrm{G}_{2} / \mathrm{M}$ toward cell cycle exit. Additional investigations of this model will broaden our understanding of how cell-extrinsic signals influence neural progenitor cell behaviors to achieve balanced production of diverse neuronal cell types in a given neural network.

\section{References}

Agathocleous M, Locker M, Harris WA, Perron M (2007) A general role of hedgehog in the regulation of proliferation. Cell Cycle 6:156-159.

Ahmad I, Dooley CM, Polk DL (1997) Delta-1 is a regulator of neurogenesis in the vertebrate retina. Dev Biol 185:92-103.

Ajioka I, Martins RA, Bayazitov IT, Donovan S, Johnson DA, Frase S, Cicero SA, Boyd K, Zakharenko SS, Dyer MA (2007) Differentiated horizontal interneurons clonally expand to form metastatic retinoblastoma in mice. Cell 131:378-390. 
Alcedo J, Ayzenzon M, Von Ohlen T, Noll M, Hooper JE (1996) The Drosophila smoothened gene encodes a seven-pass membrane protein, a putative receptor for the hedgehog signal. Cell 86:221-232.

Altshuler DM, Turner DL, Cepko DL (1991) Specification of cell type in the vertebrate retina. In: Development of the visual system. Cambridge, MA: MIT.

Austin CP, Feldman DE, Ida JA Jr, Cepko CL (1995) Vertebrate retinal ganglion cells are selected from competent progenitors by the action of Notch. Development 121:3637-3650.

Brown NL, Kanekar S, Vetter ML, Tucker PK, Gemza DL, Glaser T (1998) Math5 encodes a murine basic helix-loop-helix transcription factor expressed during early stages of retinal neurogenesis. Development 125:4821-4833.

Brown NL, Patel S, Brzezinski J, Glaser T (2001) Math5 is required for retinal ganglion cell and optic nerve formation. Development 128:2497-2508.

Buttitta LA, Edgar BA (2007) Mechanisms controlling cell cycle exit upon terminal differentiation. Curr Opin Cell Biol 19:697-704.

Cayuso J, Ulloa F, Cox B, Briscoe J, Martí E (2006) The Sonic hedgehog pathway independently controls the patterning, proliferation and survival of neuroepithelial cells by regulating Gli activity. Development 133:517-528.

Chen S, Wang QL, Nie Z, Sun H, Lennon G, Copeland NG, Gilbert DJ, Jenkins NA, Zack DJ (1997) Crx, a novel Otx-like paired-homeodomain protein, binds to and transactivates photoreceptor cell-specific genes. Neuron 19:1017-1030.

Dehay C, Kennedy H (2007) Cell-cycle control and cortical development. Nat Rev Neurosci 8:438-450.

Dorsky RI, Rapaport DH, Harris WA (1995) Xotch inhibits cell differentiation in the Xenopus retina. Neuron 14:487-496.

Dorsky RI, Chang WS, Rapaport DH, Harris WA (1997) Regulation of neuronal diversity in the Xenopus retina by Delta signalling. Nature 385:67-70.

Dyer MA, Cepko CL (2001a) The p57Kip2 cyclin kinase inhibitor is expressed by a restricted set of amacrine cells in the rodent retina. J Comp Neurol 429:601-614.

Dyer MA, Cepko CL (2001b) Regulating proliferation during retinal development. Nat Rev Neurosci 2:333-342.

Dyer MA, Cepko CL (2001c) p27Kip1 and p57Kip2 regulate proliferation in distinct retinal progenitor cell populations. J Neurosci 21:4259-4271.

Furukawa T, Kozak CA, Cepko CL (1997a) rax, a novel paired-type homeobox gene, shows expression in the anterior neural fold and developing retina. Proc Natl Acad Sci U S A 94:3088-3093.

Furukawa T, Morrow EM, Cepko CL (1997b) Crx, a novel otx-like homeobox gene, shows photoreceptor-specific expression and regulates photoreceptor differentiation. Cell 91:531-541.

Furukawa T, Morrow EM, Li T, Davis FC, Cepko CL (1999) Retinopathy and attenuated circadian entrainment in Crx-deficient mice. Nat Genet 23:466-470.

Georgia S, Soliz R, Li M, Zhang P, Bhushan A (2006) p57 and Hes1 coordinate cell cycle exit with self-renewal of pancreatic progenitors. Dev Biol 298:22-31.

Godinho L, Williams PR, Claassen Y, Provost E, Leach SD, Kamermans M, Wong RO (2007) Nonapical symmetric divisions underlie horizontal cell layer formation in the developing retina in vivo. Neuron 56:597-603.

Guo K, Wang J, Andrés V, Smith RC, Walsh K (1995) MyoD-induced expression of p21 inhibits cyclin-dependent kinase activity upon myocyte terminal differentiation. Mol Cell Biol 15:3823-3829.

Halevy O, Novitch BG, Spicer DB, Skapek SX, Rhee J, Hannon GJ, Beach D, Lassar AB (1995) Correlation of terminal cell cycle arrest of skeletal muscle with induction of p21 by MyoD. Science 267:1018-1021.

Harris WA, Hartenstein V (1991) Neuronal determination without cell division in Xenopus embryos. Neuron 6:499-515.

Hashimoto T, Zhang XM, Chen BY, Yang XJ (2006) VEGF activates divergent intracellular signaling components to regulate retinal progenitor cell proliferation and neuronal differentiation. Development 133:2201-2210.

Holt CE, Bertsch TW, Ellis HM, Harris WA (1988) Cellular determination in the Xenopus retina is independent of lineage and birth date. Neuron $1: 15-26$.

Hsu JC (1996) Multiple comparisons: theory and methods. London: Chapman and Hall.

Hufnagel RB, Riesenberg AN, Saul SM, Brown NL (2007) Conserved regu- lation of Math5 and Math1 revealed by Math5-GFP transgenes. Mol Cell Neurosci 36:435-448.

Hutcheson DA, Hanson MI, Moore KB, Le TT, Brown NL, Vetter ML (2005) bHLH-dependent and -independent modes of Ath5 gene regulation during retinal development. Development 132:829-839.

Inoue T, Hojo M, Bessho Y, Tano Y, Lee JE, Kageyama R (2002) Math3 and NeuroD regulate amacrine cell fate specification in the retina. Development 129:831-842.

Jadhav AP, Mason HA, Cepko CL (2006) Notch 1 inhibits photoreceptor production in the developing mammalian retina. Development 133:913-923.

Jensen AM, Wallace VA (1997) Expression of Sonic hedgehog and its putative role as a precursor cell mitogen in the developing mouse retina. Development 124:363-371.

Kageyama R, Ohtsuka T, Kobayashi T (2007) The Hes gene family: repressors and oscillators that orchestrate embryogenesis. Development 134:1243-1251.

Kanekar S, Perron M, Dorsky R, Harris WA, Jan LY, Jan YN, Vetter ML (1997) Xath5 participates in a network of bHLH genes in the developing Xenopus retina. Neuron 19:981-994.

Kenney AM, Rowitch DH (2000) Sonic hedgehog promotes $G_{1}$ cyclin expression and sustained cell cycle progression in mammalian neuronal precursors. Mol Cell Biol 20:9055-9067.

Kenney AM, Cole MD, Rowitch DH (2003) Nmyc upregulation by sonic hedgehog signaling promotes proliferation in developing cerebellar granule neuron precursors. Development 130:15-28.

Kenney AM, Widlund HR, Rowitch DH (2004) Hedgehog and PI-3 kinase signaling converge on $\mathrm{Nmycl}$ to promote cell cycle progression in cerebellar neuronal precursors. Development 131:217-228.

Kim J, Wu HH, Lander AD, Lyons KM, Matzuk MM, Calof AL (2005) GDF11 controls the timing of progenitor cell competence in developing retina. Science 308:1927-1930.

Kolpak A, Zhang J, Bao ZZ (2005) Sonic hedgehog has a dual effect on the growth of retinal ganglion axons depending on its concentration. J Neurosci 25:3432-3441.

Le TT, Wroblewski E, Patel S, Riesenberg AN, Brown NL (2006) Math5 is required for both early retinal neuron differentiation and cell cycle progression. Dev Biol 295:764-778.

Levine EM, Roelink H, Turner J, Reh TA (1997) Sonic hedgehog promotes rod photoreceptor differentiation in mammalian retinal cells in vitro. J Neurosci 17:6277-6288.

Lillien L (1995) Changes in retinal cell fate induced by overexpression of EGF receptor. Nature 377:158-162.

Liu W, Khare SL, Liang X, Peters MA, Liu X, Cepko CL, Xiang M (2000) All Brn3 genes can promote retinal ganglion cell differentiation in the chick. Development 127:3237-3247.

Locker M, Agathocleous M, Amato MA, Parain K, Harris WA, Perron M (2006) Hedgehog signaling and the retina: insights into the mechanisms controlling the proliferative properties of neural precursors. Genes Dev 20:3036-3048.

Long F, Zhang XM, Karp S, Yang Y, McMahon AP (2001) Genetic manipulation of hedgehog signaling in the endochondral skeleton reveals a direct role in the regulation of chondrocyte proliferation. Development 128:5099-5108.

Marquardt T, Ashery-Padan R, Andrejewski N, Scardigli R, Guillemot F, Gruss $P$ (2001) Pax6 is required for the multipotent state of retinal progenitor cells. Cell 105:43-55.

Matter-Sadzinski L, Puzianowska-Kuznicka M, Hernandez J, Ballivet M, Matter JM (2005) A bHLH transcriptional network regulating the specification of retinal ganglion cells. Development 132:3907-3921.

Mears AJ, Kondo M, Swain PK, Takada Y, Bush RA, Saunders TL, Sieving PA, Swaroop A (2001) Nrl is required for rod photoreceptor development. Nat Genet 29:447-452.

Mu X, Fu X, Sun H, Beremand PD, Thomas TL, Klein WH (2005) A gene network downstream of transcription factor Math5 regulates retinal progenitor cell competence and ganglion cell fate. Dev Biol 280:467-481.

Mu X, Fu X, Beremand PD, Thomas TL, Klein WH (2008) Gene regulation logic in retinal ganglion cell development: Isll defines a critical branch distinct from but overlapping with Pou4f2. Proc Natl Acad Sci U S A 105:6942-6947.

Nakamura K, Harada C, Namekata K, Harada T (2006) Expression of olig2 in retinal progenitor cells. Neuroreport 17:345-349. 
Neumann CJ, Nuesslein-Volhard C (2000) Patterning of the zebrafish retina by a wave of sonic hedgehog activity. Science 289:2137-2139.

Nishida A, Furukawa A, Koike C, Tano Y, Aizawa S, Matsuo I, Furukawa T (2003) Otx2 homeobox gene controls retinal photoreceptor cell fate and pineal gland development. Nat Neurosci 6:1255-1263.

Ohsawa R, Kageyama R (2008) Regulation of retinal cell fate specification by multiple transcription factors. Brain Res 1192:90-98.

Pan L, Deng M, Xie X, Gan L (2008) ISL1 and BRN3B co-regulate the differentiation of murine retinal ganglion cells. Development 135:1981-1990.

Poché RA, Kwan KM, Raven MA, Furuta Y, Reese BE, Behringer RR (2007) Lim1 is essential for the correct laminar positioning of retinal horizontal cells. J Neurosci 27:14099-14107.

Riesenberg AN, Le TT, Willardsen MI, Blackburn DC, Vetter ML, Brown NL (2009) Pax6 regulation of Math5 during mouse retinal neurogenesis. Genesis 47:175-187.

Rompani SB, Cepko CL (2008) Retinal progenitor cells can produce restricted subsets of horizontal cells. Proc Natl Acad Sci U S A 105:192-197.

Rothschild G, Zhao X, Iavarone A, Lasorella A (2006) E proteins and Id2 converge on p57Kip2 to regulate cell cycle in neural cells. Mol Cell Biol 26:4351-4361.

Rowan S, Cepko CL (2004) Genetic analysis of the homeodomain transcription factor Chx10 in the retina using a novel multifunctional BAC transgenic mouse reporter. Dev Biol 271:388-402.

Ruiz i Altaba A, Palma V, Dahmane N (2002) Hedgehog-Gli signalling and the growth of the brain. Nat Rev Neurosci 3:24-33.

Sánchez-Camacho C, Bovolenta P (2008) Autonomous and nonautonomous Shh signalling mediate the in vivo growth and guidance of mouse retinal ganglion cell axons. Development 135:3531-3541.

Sasaki H, Nishizaki Y, Hui C, Nakafuku M, Kondoh H (1999) Regulation of Gli2 and Gli3 activities by an amino-terminal repression domain: implication of Gli2 and Gli3 as primary mediators of Shh signaling. Development 126:3915-3924.

Shibasaki K, Takebayashi H, Ikenaka K, Feng L, Gan L (2007) Expression of the basic helix-loop-factor Olig2 in the developing retina: Olig2 as a new marker for retinal progenitors and late-born cells. Gene Expr Patterns 7:57-65.

Shimojo H, Ohtsuka T, Kageyama R (2008) Oscillations in notch signaling regulate maintenance of neural progenitors. Neuron 58:52-64.

Shkumatava A, Neumann CJ (2005) Shh directs cell-cycle exit by activating p57Kip2 in the zebrafish retina. EMBO Rep 6:563-569.

Shkumatava A, Fischer S, Müller F, Strahle U, Neumann CJ (2004) Sonic hedgehog, secreted by amacrine cells, acts as a short-range signal to direct differentiation and lamination in the zebrafish retina. Development 131:3849-3858.

Soriano P (1999) Generalized lacZ expression with the ROSA26 Cre reporter strain. Nat Genet 21:70-71.

Spence SG, Robson JA (1989) An autoradiographic analysis of neurogenesis in the chick retina in vitro and in vivo. Neuroscience 32:801-812.

Stenkamp DL, Frey RA (2003) Extraretinal and retinal hedgehog signaling sequentially regulate retinal differentiation in zebrafish. Dev Biol 258:349-363.
Sukhanova MJ, Deb DK, Gordon GM, Matakatsu MT, Du W (2007) Proneural basic helix-loop-helix proteins and epidermal growth factor receptor signaling coordinately regulate cell type specification and cdk inhibitor expression during development. Mol Cell Biol 27:2987-2996.

Turner DL, Cepko CL (1987) A common progenitor for neurons and glia persists in rat retina late in development. Nature 328:131-136.

van den Heuvel M, Ingham PW (1996) smoothened encodes a receptor-like serpentine protein required for hedgehog signalling. Nature 382:547-551.

Vetter ML, Brown NL (2001) The role of basic helix-loop-helix genes in vertebrate retinogenesis. Semin Cell Dev Biol 12:491-498.

Viczian AS, Vignali R, Zuber ME, Barsacchi G, Harris WA (2003) XOtx5b and XOtx2 regulate photoreceptor and bipolar fates in the Xenopus retina. Development 130:1281-1294.

Wall DS, Mears AJ, McNeill B, Mazerolle C, Thurig S, Wang Y, Kageyama R, Wallace VA (2009) Progenitor cell proliferation in the retina is dependent on Notch-independent Sonic hedgehog/Hes1 activity. J Cell Biol 184:101-112.

Wang SW, Kim BS, Ding K, Wang H, Sun D, Johnson RL, Klein WH, Gan L (2001) Requirement for math5 in the development of retinal ganglion cells. Genes Dev 15:24-29.

Wang Y, Dakubo GD, Thurig S, Mazerolle CJ, Wallace VA (2005) Retinal ganglion cell-derived sonic hedgehog locally controls proliferation and the timing of RGC development in the embryonic mouse retina. Development 132:5103-5113.

Wang YP, Dakubo G, Howley P, Campsall KD, Mazarolle CJ, Shiga SA, Lewis PM, McMahon AP, Wallace VA (2002) Development of normal retinal organization depends on Sonic hedgehog signaling from ganglion cells. Nat Neurosci 5:831-832.

West-Mays JA, Zhang J, Nottoli T, Hagopian-Donaldson S, Libby D, Strissel KJ, Williams T (1999) AP-2alpha transcription factor is required for early morphogenesis of the lens vesicle. Dev Biol 206:46-62.

Wetts R, Fraser SE (1988) Multipotent precursors can give rise to all major cell types of the frog retina. Science 239:1142-1145.

Willardsen MI, Suli A, Pan Y, Marsh-Armstrong N, Chien CB, El-Hodiri H, Brown NL, Moore KB, Vetter ML (2009) Temporal regulation of Ath5 gene expression during eye development. Dev Biol 326:471-481.

Yang X, Cepko CL (1996) Flk-1, a receptor for vascular endothelial growth factor (VEGF), is expressed by retinal progenitor cells. J Neurosci 16:6089-6099.

Yang XJ (2004) Roles of cell-extrinsic growth factors in vertebrate eye pattern formation and retinogenesis. Semin Cell Dev Biol 15:91-103.

Yang Z, Ding K, Pan L, Deng M, Gan L (2003) Math5 determines the competence state of retinal ganglion cell progenitors. Dev Biol 264:240-254.

Yaron O, Farhy C, Marquardt T, Applebury M, Ashery-Padan R (2006) Notch1 functions to suppress cone-photoreceptor fate specification in the developing mouse retina. Development 133:1367-1378.

Young RW (1985a) Cell differentiation in the retina of the mouse. Anat Rec 212:199-205.

Young RW (1985b) Cell proliferation during postnatal development of the retina in the mouse. Brain Res 353:229-239.

Zhang XM, Yang XJ (2001) Regulation of retinal ganglion cell production by Sonic hedgehog. Development 128:943-957. 